\title{
EFEITO DA UMIDADE DO SOLO NO DESENVOLVIMENTO DE MUDAS DE CEBOLA (Allium oepa L.)
}

JOSÉ ANTONIO DA SILVA

Orientador: Prof. Dr. RUBENS SCARDUA

Dissertação apresentada à Escola Superior de Agricultura "Luiz de Queiroz", da Universidade de São Paulo, para obtenção do título de Mestre em Irrigação e Drenagem.

PIRACICABA

Estado de São Paulo - Brasil Julho - 1986 
A minha mäe

ANGELINA

DEDICO.

A minha esposa MARGARETE

$e$ aos meus filhos GIOVANIO Q VIVIANE

OFEREÇO. 


\section{AGRADECIMENTOS}

A Deus, pela fé e perseverança concedida em todos os momentos.

Ao Prof. Dr. Rubens Scardua pela orientação, amizade e apoio recebido no decorrer do curso e na realização deste trabalho.

Ao Prof. Dr. Décio Barbin pelo auxílio na elaboração das anālises estatísticas.

Ao colega e prof. Tarlei Arriel Botrel pela amizade e sugestões ao trabalho.

Aos funcionários do Departamento de Engenharia Rural pela ajụ da e amizade.

A senhora Maria Vieira Quadros nossa secretäria por seu. apoio e dedicação.

Aos colegas Valdir Bento dos Santós e Morel Pereira Barbosa Filho pela amizade, sugestões e colaboração na condução do experimento.

Aos professores do Departamento de Engenharia Rural pelo con vívio amigo e pela contribuição da minha formação.

A Associação de Crédito e Assistência Rural do Estado de Santa Catarina (ACARESC) pela oportunidade concedida à participação do curso.

Aos colegas do curso pelo convívio amigo.

A todos que contribuiram direta ou indiretamente para a elaboração deste trabalho. 
RESUMO $\ldots \ldots \ldots \ldots \ldots \ldots \ldots \ldots \ldots \ldots \ldots \ldots \ldots \ldots \ldots \ldots \ldots \ldots \ldots \ldots$

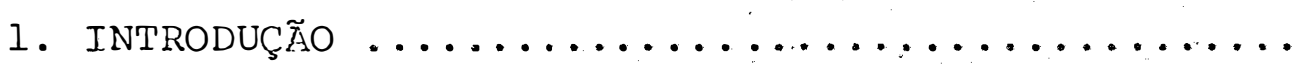

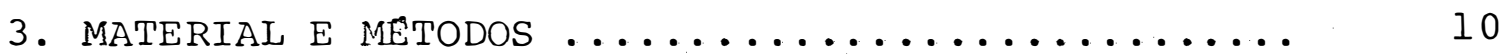

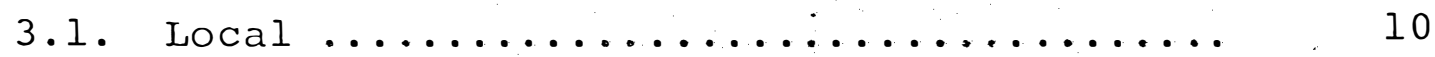

3.2. Solo e clima.$\ldots \ldots \ldots \ldots \ldots \ldots \ldots \ldots \ldots \ldots$

3.3. Curva característica da ägua no solo ..... 12

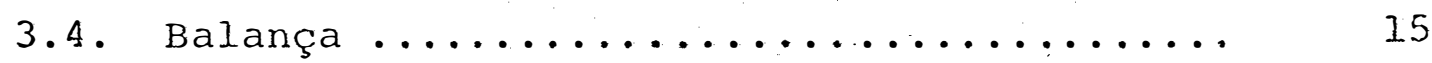

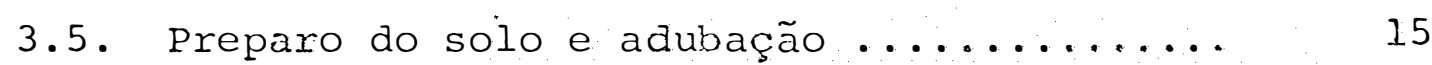

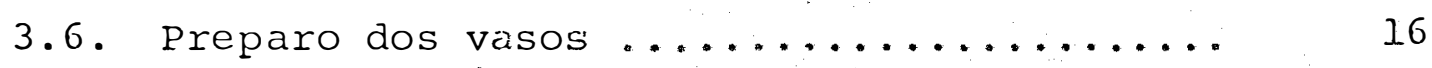

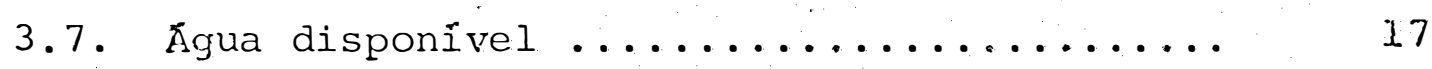

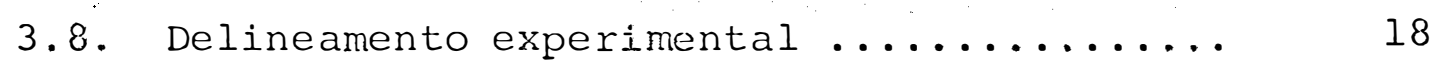

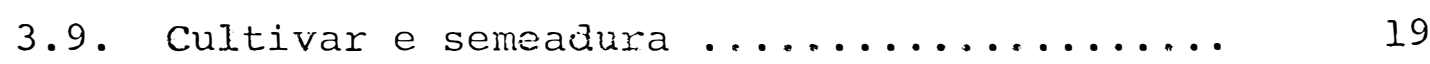

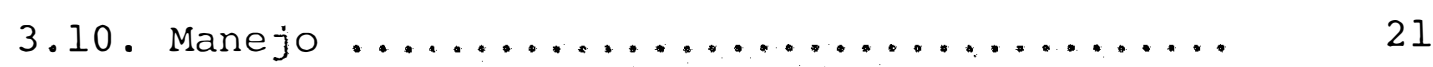

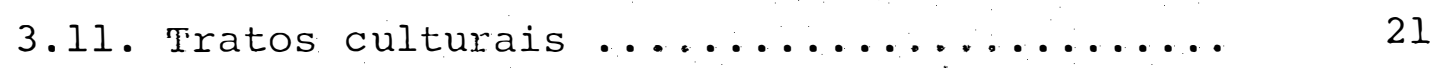

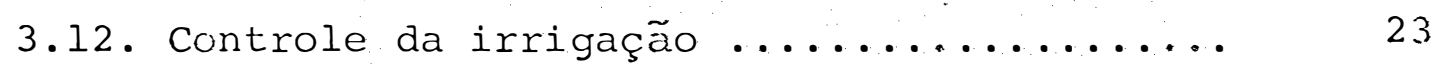

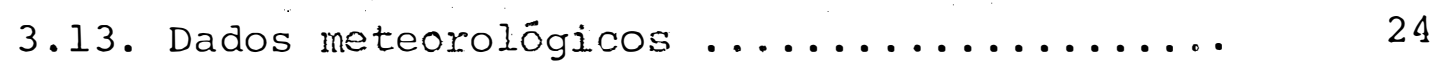

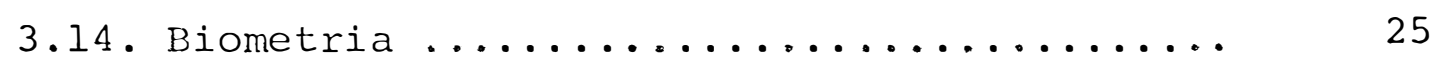

3.15. Estimativa da evapotranspiração de referên cia utilizando o tanque classe "A" ...... 26

3.16. Estimativa do coeficiente da cultura ..... 27

3.17. Anālise estatistica $\ldots \ldots \ldots \ldots \ldots \ldots \ldots . \ldots \ldots$

4. RESULTADOS E DISCUSS $\tilde{O} O \ldots \ldots \ldots \ldots \ldots \ldots \ldots \ldots . \ldots \ldots$

4.1. Efeito dos tratamentos na altura das mudas. 30

4.2. Efeito dos tratamentos na produção de maté

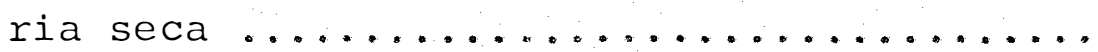


4.3. Efeito dos tratamentos no diâmetro do pseu-

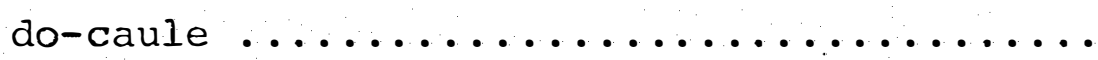

4.3.1. Frequềncia do diâmetro do pseudo-cau

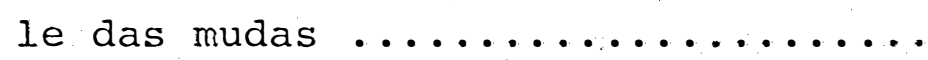

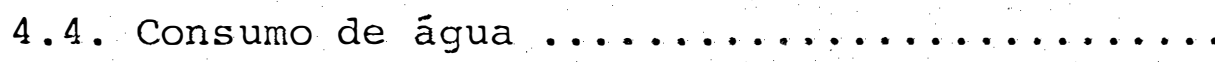
45

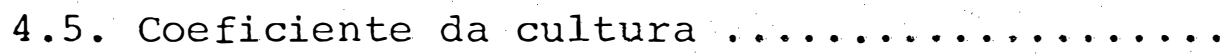

5. CONCLUSÕes $\ldots \ldots \ldots \ldots \ldots \ldots \ldots \ldots \ldots \ldots \ldots$

6. Literatura citada $\ldots \ldots \ldots \ldots \ldots \ldots \ldots \ldots$ 


\section{LISTA DE TABELAS}

TABELA NO

Página

01 Granulometria e classe textural .........

02 Peso total dos vasos nos dois solos ......

03 Teores de āgua no solo na capacidade de campo e ponto de murcha em percentagem nos

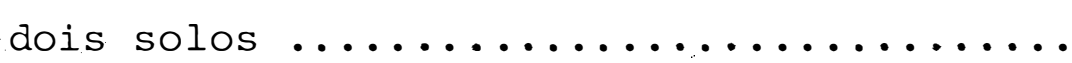

04 Valores calculados para $\odot$ controle da irri

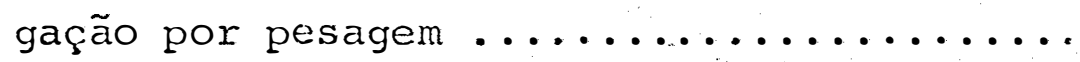

05 Dados meteorológicos $\ldots \ldots \ldots \ldots \ldots \ldots$

06 Valores do coeficiente de conversão do tan que classe "A" (Kp) para a estimativa da evapotranspiração de referência (ETO) ....

07 Volume de água aplicado em milímetro por

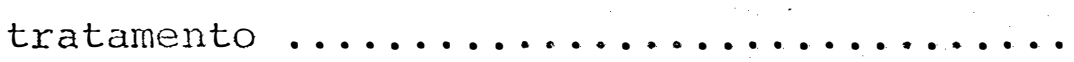

08 Médias originais obtidas de 15 mudas por tratamento, por repetição, em relação à alturá, diâmetro do pseudo-caule e matéria seca das mudas de cebola na colheita .....

09 Análise de variância da altura das mudas.

10 Valores médios da altura das mudas (cm) em relação aos quatro níveis de âgua disponí

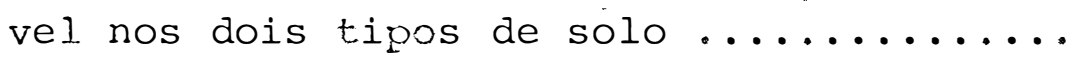


vii.

TABELA NQ

Pāgina

11 Análise de variância da matéria seca ....

12 Valores médios da produção de matéria seca (g) em relação aos quatro níveis de āgua disponível nos dois tipos de solo..

13 Análise de variância do diâmetro do ṕseu-

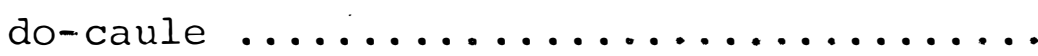

14 Valores médios do diâmetro do pseudo-caule (mm) em relação aos quatro níveis de água disponível nos dois tipos de solo..

15 Valores médios em mm/dia de ãgua consumida pelas muaas de cebola nos dois tipos

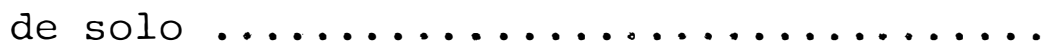

16 Coeficiente da cultura por período paraos quatro níveis de água disponível e solo. 
01 Localização e instalação do experimento .

02 Curva característica da água no solo (TRE)

03 Curva característica da água no solo (LiVm).

04 Cobertura do experimento com tecido de algodão

05 Cobertura do experimento com plástico trans

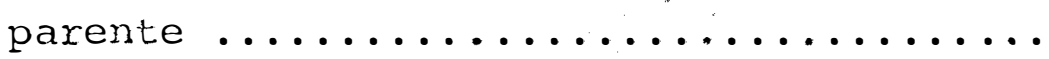

06 Pesagem dos vasos para o controle da ir-

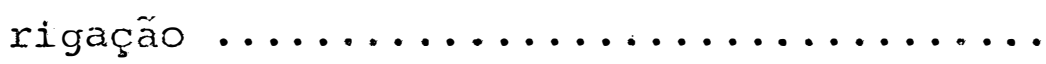

07 Posto meteorológico $\ldots \ldots \ldots \ldots \ldots \ldots \ldots$

08 Altura das mudas de cebola em função dos quatro níveis de água em dois tipos de so $10 \ldots \ldots \ldots \ldots \ldots \ldots \ldots \ldots \ldots . . \ldots \ldots \ldots$

09 Produção de matéria seca em função dos quatro níveis de água em dois tipos de so

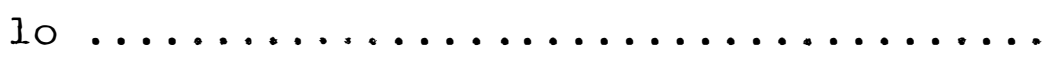

10 Diâmetro do pseuco-caule em função. dos quatro níveis de ấguà em dois tipos de so $10 \ldots \ldots \ldots \ldots \ldots \ldots \ldots \ldots \ldots \ldots \ldots \ldots$.

11 Percentagern da frequência do diämetro nos quatro níveis de ägua disponível no TRE. 
12 Percentagem da frequîencia do diâmetro nos quatro níveis de āgua disponível no IVm.

13 Representação gräfica do coeficiente de cultura ( $\mathrm{KC}$ ) em relação aos quatro níveis de āgua disponível nos dois tipos de so-

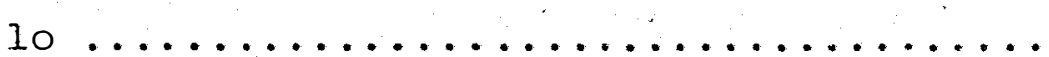


EFEITO DA UMIDADE DO SOLO NO DESENVOLVIMENTO

DE MUdAS DE CEBOLA (Allium cepa L.).

\section{Autor: JOSE ANTONIO DA SILVA}

Orientador: Prof. Dr. RUBENS SCARDUA

RESUMO

O presente trabalho teve como objetivo:verificar os efeitos de níveis de água, aplicado em doj.s tipos de so lo, na formação de mudas de cebola em sementeira.

Estudou-se, em condições de campo em vasos, utilizando-se quatro níveis de água disponível e dois tipos de solo; com seis repetições em distribuição inteiramente casualizada.

A cultivar utilizada foi a baia periforme precoce, e os solos utilizados foram o Latossolo Vermelho Amarelo ( $(V M)$ e a Terra Roxa Estruturada (TRE).

Após vinte dias da semeadura da cebola, iniciou-se o controle do consumo de água disponível, utilizandose os quatro níveis assim distribuídos: irrigar quando fosse consumido $10,30,50$ e 70\% da água disponível do solo.

As variáveis analisadas foram: altura das mudas; produçäo de matéria seca; diâmetro do pseudo-caule, sendo a última variável, de maior importância na análise da qualidade das rnu das. Foi determinado tanbém o coeficiente da cultura (KC) . 
Houve diferença significativa, a nível de $1 \%$ de probabilidade, entre os nj̃veis de āgua pré-estabelecidos, sendo que o tratamento preconizando irrigar quando $70 \%$ de água disponível do solo fosse consumida, foi o que produziu mudas de pior qualidade. Mesmo não havendo diferença significati va entre os três primeiros níveis de água disponível, ou seja, 10,30 e $50 \%$ de consumo, o tratamento $30 \%$ de consumo de água disponível foi o que produziu as mudas de melhor qualidade em ambos os solos. No LVm as mudas produzidas foram de melhor qualidade, quando comparadas as produzidas no TRE, ressaltando se que no LVm houve uma diminuiçăo no estande em aproximadamen te 40\%, devido o ataque de doenças. Em ambos os solos, quando utilizou-se o tratamento 30\% de consumo de āgua disponível, aproximadamente $90 \%$ das mudas obtidas tinham o diâmetro do pseudo-caule superior a 3,0 mm. 
THE EFFECT OF SOIL HUMIDITY ON THE DEVELOPMENT OF ONION SEEDLINGS (Allium cepa L.).

\author{
Author: JOSE ANTONIO DA SILVA \\ Adviser: Prof. Dr. RUBENS SCARDUA
}

\title{
SUMAARY
}

The present work aims at studyng the effects of different water level treatments in two soil types on the development of onion seedlings in seedbeds.

Under field conditions, the experiment was carried out whith vases using four water level tretaments and two, kinds of soil. Six replications were made at an enterely randon distribution.

The cultivar adopted was early baia periforme and the soils used were Red Yellow Latossol and "Terra Roxa Estruturada".

Twenty days after onion was seeded water control was started comprising four different water treatments: seeds would be irrigated as soon as a 10,30, 50 and 70\% water level was taken up.

The following variables were analyzed: plant height; dry matter production and pseudo-stalk diameter; the latter being the main factor on seedling quality analysis. In addition, the crop coefficient $(\mathrm{Kc})$ was determined. 
At $1 \%$ probability level, significative differences were observed among the four water treatments. The $70 \%$ treatment produced the poorest plants. Even if thre was no relevant difference between the three first water treatments $(10,30$ and $50 \%)$, the $30 \%$ level provided the best seedinlings in both types of soil.

In Red Yellow Latossol seedling, produced were of better quality than those in (Terra Roxa Estruturada); in spite of this, in Red Yellow Latossol a $40 \%$ reduction was felt in stands, due to seedlings diseases. In both soil types, however, when the $30 \%$ water treatment was adapted, the pseudo stalk diameter measured more than $3,0 \mathrm{~mm}$ in about $90 \%$ of onion seedlings. 


\section{INTRODUÇz̃̃O}

No Brasil, a cebola (Allium cepa L.), é consumida como um condimento e não como um alimento, apresentando um consumo médio de $3,5 \mathrm{~kg}$ "per capita" e por ano e sua projeção para 1985 foi estimada em 4,0 kg/hab/ano (SUPLAN / MA). Três regiões brasileiras compostas pelos estados do Rio Grande do Sul, Santa Catarina, são Paulo, Minas Eerais, Bahia e Pernambuco, são responsāveis por $95 \%$ da produçäo nacional de cebola.

o sucesso da cultura da cebola está diretamente relacionado com a qualidade e quantidade das mudas utiliza das no transplante. A má formação das mudas tem como consequências uma queda na produtividade e uma diminuição na ărea de plantio e conseqüentemente menor produção. Para que o pro dutor tenha sucesso numa cultura de cebola, é necessário que produza mudas, em quantidade e qualidade, compatíveis com o alto rendimento da cultura. 
Tem-se verificado que a má formação de mudas, está rélacionada com a falta de um bom manejo da água de irrí gação nas sementeiras. Para evidenciar mais o problema, os produtores do Rio Grande do Sul e Santa Catarina, têm conseguido em média 100.000 mudas $/ \mathrm{kg}$ de semente em condições de transplante, sem no entanto, considerar a qualidade destas mudas. Este rendimento é considerado muito baixo, pois sabese que, em condições edafoclimáticas adequadas, pode-se produzir até 220.000 mudas $/ \mathrm{kg}$ de semente, e um dos fatores que contribui para este decréscimo, na produção de mudas é a falta de água nas sementeiras.

Apesar da importância do manejo de āgua, nesta - fase de produção de mudas, poucos trabalhos são encontrados na literatura.

O presente trabalho tem como objetivo verificar o efeito de níveis de água, aplicados em dois tipos de so 10, na formação de mudas de cebola em sementeira. 


\section{REVIS $\tilde{A} O$ DE LITERATURA}

Em regiões, onde o plantio da cebola é realizado através do método de transplante, como no caso o Brasil, as características das mudas e a época de transplante, desempenham papel importante na redução do florescimento prematuro e conseqüentemente na produção de buibo de cebola.

Na Califórnia, Davis e Jones (1944) citados por JONES e MANN (1963), realizaram um trabalho com a cuj.tivar grano, utilizando diversos tamanios de diâmetro de mudas e, constataram que mudas com diâmetro inferior a 6,2 mm apresentaram insiginificante percentagem de florescimento precoce, sendo que acima deste limite, a ocorrência do florescimen to precoce foi diretamente proporcional ao diâmetro da muda, e que, acima de $19 \mathrm{~mm}$ de diâmetro todas as plantas floresceram. Concluíram, para aquelas condições, que a produtividade decresce quando se utiliza mudas com diâmetro superior a 6,2 mm. En outro experimento, realizado em Malpitas, com a 
mesma cultivar, a produção e o peso médio dos bulbos comerciais aumentaram proporcionalmente com o tamanho das mudas, com exceção daqueles com diâmetro superior a $13 \mathrm{~mm}$, devido a ocorrência de elevado índice de florescimento prematuro.

Voster, citado por SILVA et alii (1971), traba Ihando com mudas de diâmetro, aproximadamente igual ao diâmetro de um läpis, concluiu que estas produziram bulbos de tamanho médio a grande. O autor obsérvou que, o atraso progres sivo no plantio de mudas, prómoveu um decréscimo na produção total e, ao mesmo tempo, uma redução no diâmetro do bulbo.

SILVA (1983), em trabalho desenvolvido em Vi-Çosa, MG, concluiu que o tamanho da muda afetou a produtivi dade e que, a percentagem de plantas florescidas, aumentou li nearmente com o tamanho da muda. Vale salientar que o Elores cimento tem estreita relação com o fotoperíodo e varia em fun ção da exigência varietal.

JONES E MANN (1963), salientaram a importância. da época de plantio da cebola e o tamanho das mudas, especial mente em regiões onde o plantio é efetuado no final da estação fria. Isso porque, se houver uma grande incidência de temperaturas baixas, durante o periodo de crescimento vegetativo, estas podem induzir um florescimento prematuro, reduzindo a produção comercial de bulbos.

SILVA et alii (1971), verificando o efeito do tamanho das mudas no rendimento da cebola, concluíram que a produção aumentou linearmente com o aumento do tamanho das mu 
das até $6,0 \mathrm{~mm}$ de diâmetro, valor este, utilizado como limite superior do diâmetro das mudas.

$$
\text { Verma et alii (1971), citado por VIZzorro (1984), }
$$

efetuando estudos conjuntos entre épocas de plantio e idade das mudas, concluíram que mudas com oito semanas de idade foram as mais produtivas. por sua vez, a utilização de mudas mais jovens ou mais velhas causaram redução na produção, sendo que as mudas mais jovens mostraram baixa capacidade de sobrevivência após otransplante, reduzindo consequientemente o es tande final.

Há dois conceitos fundamentais em pesquisa, pa ra explicar a disponibilidade de água às plantas sem afetar o seu desenvolvimento. O primeiro foi verificado por VEIHMEYER e HENDRICKSON (1942), os quais concluíram que, todas as funções das plantas prosseguem normalmente, enquanto a umidade permanece acima do Ponto de Murchá Permanente (PMP). O segun do, apresentado por RICHARDS e WADLEIGH (1952), onde afirmaram que o crescimento vegetativo das culturas diminui progressivamente, ä medida que o teor de umidade do solo decresce, e as plantas podem sentir falta de äçua, antes de atingir o seu Ponto de Murcha Permanente. Nenhum dos conceitos mencionados foi capaz de provar suas hipöteses, considerando o conjunto de fatores que afetam o regime hidräulico do sistema solo-planta - atmosfera como um todo. Cada um tirou suas conclusões, por meio de experiências em condições específicas e não bem definídas . 
Stanhill (1957), citado por KLAR (1967), estudando às duas teorias, através de oitenta trabalhos publicados por diferentes autores, verificou que sessenta e seis deles responderam significativamente as diferentes condições de umidade ocorrida dentro do intervalo de água disponível, com os maiores rendimentos associados aos altos teores de umidade.

\section{DEMATTE et alii (1971), em trabalho realizado}

em Monte Alegre - SP, com o objetivo de determinar a influên cia da irrigação na formação de mudas de cebola, concluíram que não houve diferença significativa, quando as mesmas foram irrigadas ao nível crítico de 25,50 e $90 \%$ do intervalo de āgua disponível, sendo que houve diferença em relação a produ ção de mudas com diâmetro de até $3,0 \mathrm{~mm}$; e que o tratamento ao nível crítico de $25 \%$ do intervalo de āgua disponível foi o que mais produziu mudas com este diâmetro. Os intervalos uti lizados pelos autores em relação aos diâmetros foram: 0-3mm, 3-6mm e maior que $5 \mathrm{~mm}$. Os mesmos autores, determinando o con sumo de água e a Erequêencia de irrigação para a fase de forma ção de mudas, e considerando uma dotação de $70 \%$ de ägua disponível, obtiveram os seguintes, resultados: o consumo mëdio de âgua durante o ciclo foi de aproximadamente 3,5 mm/dia, e 0 intervalo de irrigação de três dias.

Segundo JONES e MANN (1963), o cultj.vo da cebola é mais comum nos países de clima quente, onde a culti var se desenvolve no inverno. Para isto, necessita de cultivares de dias curtos a fim de que haja formação de bulbos. As 
mudas devem ter entre 6 e $8 \mathrm{~mm}$ de diâmetro e 180 a 250 mm de altura para o transplante, porque mudas maiores perfilham, reduzem o número de bulbos comerciais e apresentam florescimen to prematuro.

KLAR (1972), trabalhando com a cultura da cebo la em Piracicaba, SP., obteve maiores produções quando utilizou teores mais elevados de umidade do solo: $-0,5$ e $-1,0$ bar, em comparaçao aos teores de $-6,0$ e $-15,0$ bar. O mesmo autor verificou, trabalhando com gladíolos, que as respostas foram diferentes, confirmando que as plantas respondem de maneira diferente as variações de umidade do solo.

KLAR (1967), estudando a influência da umidade do solo sobre a cultura da cebola, concluiu que as maiores produções foram alcançadas, quando se mantinha a tensão da água do solo na faixa de $-0,5$ bar, observando tambérn não haver diferença quanto ao nümero de dias no ciclo vegetativo da cultura.

COSTA FILHO et alii. (1975), avaliando o efeito de níveis de umidade na produção de cebola, em Petrolina - PE, encontraram uma maior produção, quando os níveis de ăgua eram mantidos entre a capacidade de campo e 75응 de ăgua disponível. ABREU et alii (1977), estudando a produção de cebola sob diferentes níveis de irrigação, em Petrolina - PE, verificaram que o tratamento mantido ao nível de $-0,1$ bar, pro duziu $81,7 \%$ mais bulbos de cebola do que a média dos demais tra tamentos, a $-0,5 ;-1,0 ;-2,0$ e $-4,0$ bar. 
SILVA E ARAUJO (1975), trabalhando com cinco níveis de āgua disponível, verificaram que a melhor produção alcançada foi aquela obtida, quando se mantinha o solo 75 a 100\% de āgua disponível.

KLAR et alii (1967), estudando as: necessida des de água na cultura da cebola, e utilizando quatro níveis de água disponível, 75, 50, 25 e 0\%, concluiram que o melhor nível para o desenvolvimento da cultura, no que diz respeito ao rendimento de bulbo, foi ṕroporcionado pela manutenção do teor de água do solo superior a 75\% da água disponível, ou se ja, tensão inferior a $-0,5$ bar.

VIZzotTo (1984), em trabalho desenvolvido, em Ituporanga - SC; avaliando o efeito do tamanho das mudas e da época de transplante, sobre a produção comercial de bulbos de cebola e utilizando mudas de diâmetro $2,0 \mathrm{~mm}$, de 2,1 a 3,0 $\mathrm{mm}$; de 3,1 a $4,0 \mathrm{~mm}$; de 4,1 a $5,0 \mathrm{~mm}$ i de 5,1 a $6,0 \mathrm{~mm}$ e 6,0 mm, em diferentes épocas de plantio, concluiu que, para aque la região, as mudas $\operatorname{com} 4,1$ a $6,0 \mathrm{~mm}$ de diâmetro do pseudocaule são as mais indicadas, proporcionando maior produtivida. de de bulbos comerciais.

O fechamento dos estômatos em resposta ao déficit hídrico, é um poderoso mecanismo regulador da perda de água pela planta, reduzindo o desenvolvimento do estresse. Contudo, TURNER (1975), refere-se a que esse processo não evita completamente o incremento de estresse à planta (BEGG e TURNER, 1976). 
De acordo com KRAMER (1963), se o crescimento da planta é controlado pelo déficit interno de água e turgor celular, o crescimento e a produção estão sempre correlaciona dos com a umidade do solo.

O fotoperíodo e a temperatura são os dois fatores limitantes à produção de cebola em qualquer região do mundo, pois condicionam a formação e o desenvolvimento do bul bo. Somente haverá estímulo para a iniciação do bulbo; se fo rem satisfeitas as exigências fotoperiódicas da variedade cul tivada, que constitui o chamado fotoperíodo crítico, que é uma característica da variedade (JONES e MANN, 1963 e TORRES; 1951). A cebola é uma planta de dia longo para a formação de bulbo, que somente ocorrerā, quando o fotoperíodo for igual ou superior ao mínimo exigido pela variedade. Satisfeitas as exigências fotoperiódicas, haverá a formação de bulbos se a temperatura for favorável (REES,. 1981 e STEER, 1980). 


\section{MATERIAL E METODO}

3.1. Iocal

O experimento foi instalado em ārea próxima ao Departamento de Engenharia Rural da Escola Superior de Agricultura "Luiz de Queiroz", em Piracicaba, S.P., cujas coorde-

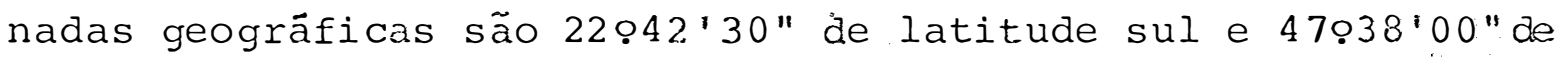
longitude oeste, a 580 metros de altitude. A ărea experimen tal foi isolada por uma cerca de arame farpado.

o experimento foi conduzido em vasos plásticos, com as dimensões de $25 \mathrm{~cm}$ de diâmetro na sua parte superior e $24 \mathrm{~cm}$ de altura, instalados sobre dois estrados de madeira, a una altura de $60 \mathrm{~cm}$ da superfície do solo, distanciados em dois metxos um do outro (Figura 1 ): 


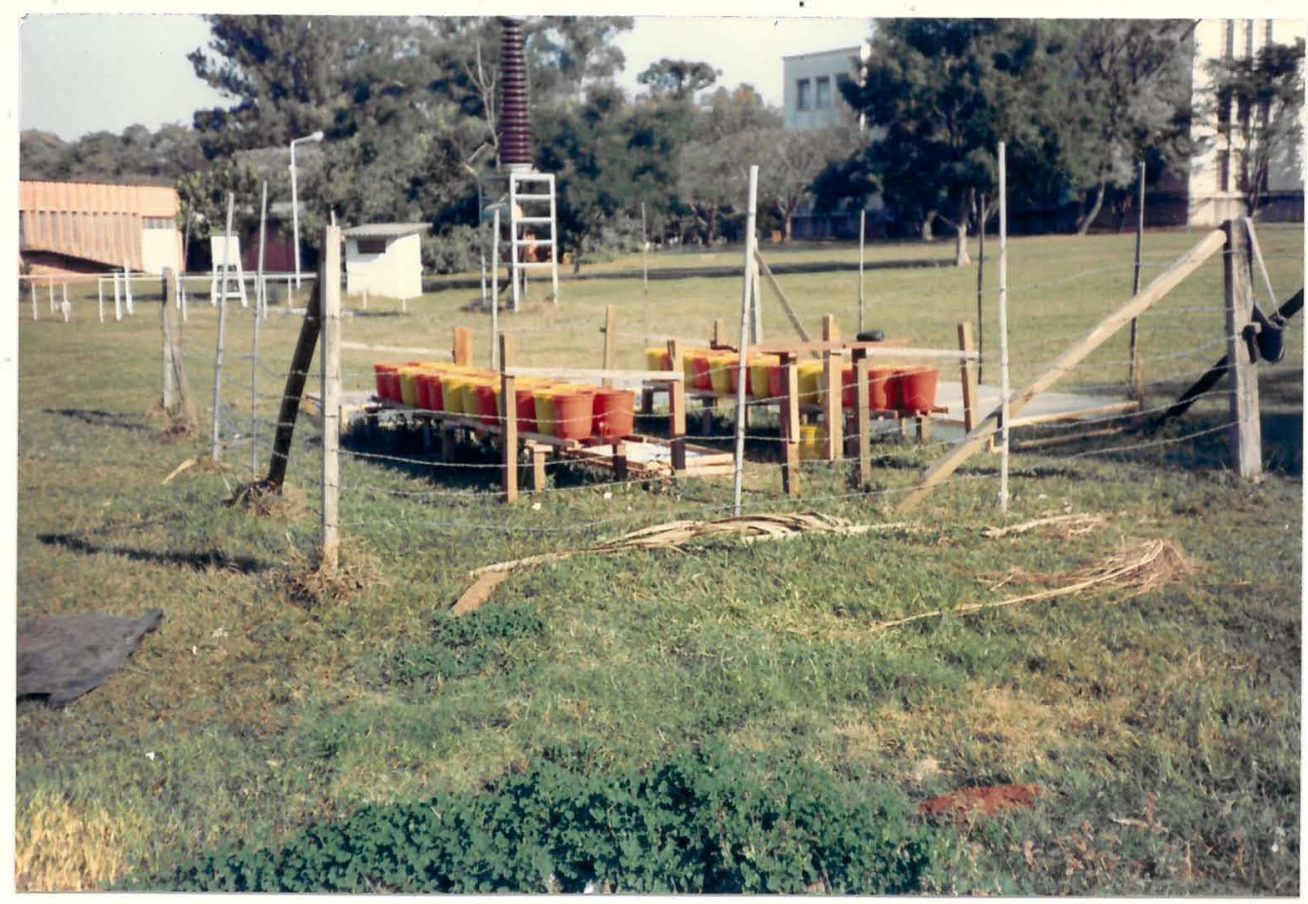

Figura 1. Localização e instalação do experimento.

\subsection{Solo e clima}

O clima da região é o Cwa, pela classifj.cação climātica de Köppen, ou seja, subtropical ürnido, com estiagem no inverno, e temperatura média no mês mais ferio inferior a 189C e, no mês mais quente superior a 229C, também cienominado de tropical de altitude por PAES de CAMARGO et alii. (1974) .

O presente trabalho foi realizacio em dois so-los pertencentes, segundo RANZANI et alii (1966), às unidades taxonômicas 'I'erra Roxa Estruturada Eutrófico textura franco argilosa (TRE) e Latossolo Vermelho Amarelo Distrófico textura franco arenosa (LVm), ou respectivamente fllísol. e Oxi- 
sol pela 7ạ Aproximação do Soil Survey staff (1975).

Tabela 1. Granulometria e classe textural.

\begin{tabular}{lccccl}
\hline Solo & $\begin{array}{c}\text { Profundidade } \\
\text { cm }\end{array}$ & $\begin{array}{c}\text { Areia } \\
\%\end{array}$ & $\begin{array}{c}\text { Silte } \\
\%\end{array}$ & $\begin{array}{c}\text { Argila } \\
\%\end{array}$ & $\begin{array}{l}\text { Classe } \\
\text { textural }\end{array}$ \\
\hline TRE & $0-25$ & 33,9 & 27,5 & 38,4 & Franco argiloso \\
LVm & $0-25$ & 83,0 & 1,2 & 15,6 & Franco arenoso \\
\hline
\end{tabular}

Fonte: Carta de Solos do Município de Piracjcaba (1966)

\subsection{Curva característica da água no solo}

A curva característica da água no solo foi ela borada por secamento com amostras deformadas, retiradas a pro fundidade de $0-25 \mathrm{~cm}$. A determinação foi efetuacia no laboratório de Física de Solos do Departamento de Engenharia Rural da ESALQ, de acordo com o roteiro de determinação da curva do mesmo departamento, conforme metodologia estabelecida por RICHARDS (1931). As amostras de solo, apös a saturação, foram submetidas as tensões de 0,01 Mpa; 0,03 Mpa; 0,1 Mpa; 0,6 Mpa e 1,5 Mpa, nas câmaras de pressão de Richarás, da Soil Moistü re Equipament Co. Os resultados foram plotados em papel Mono Iog conforme ilustram as Figuras 2 e 3 . 


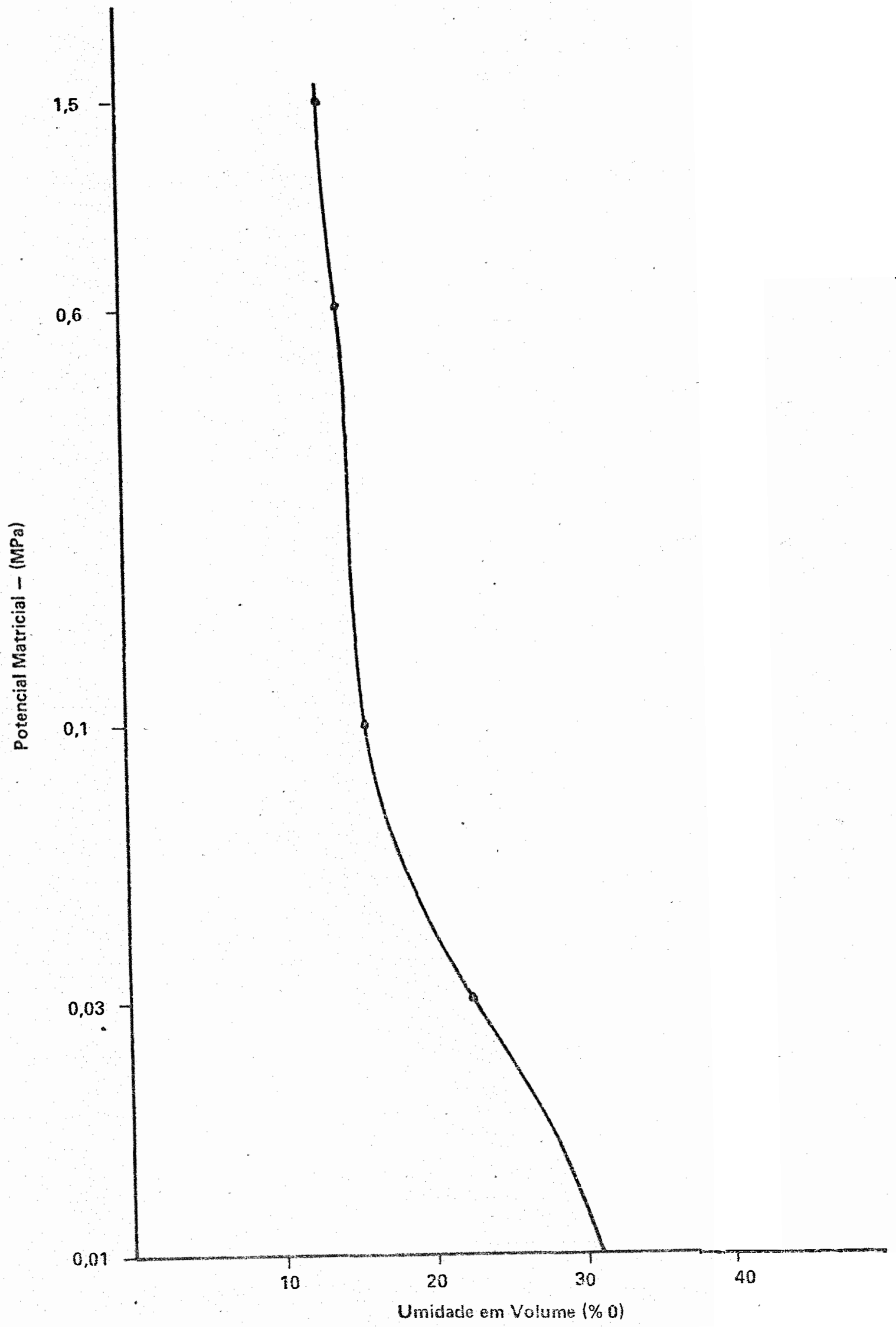

Figura - Curva Caracteristica da Agua no Solo - TRE 


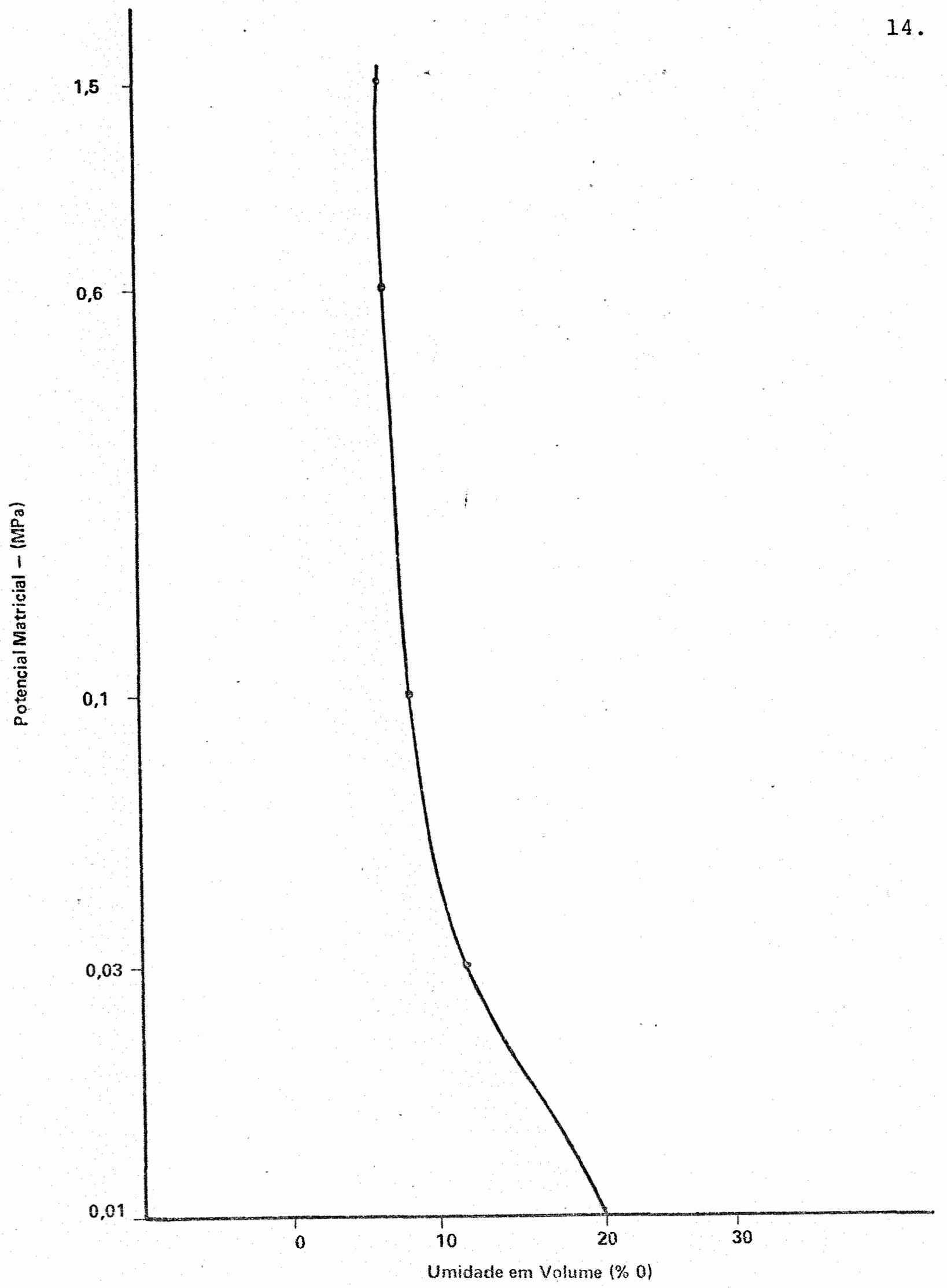

Figura 3 - Curva Característica da Água no Solo - LVm 
3.4. Balança

Utilizou-se uma balança mecânica de prato, mar ca "Solution", com capacidade de $20 \mathrm{~kg}$ e sensibilidade de uma grama, pertencente ao Departamento de Engenharia Rural da ESALQ.

A balança foi utilizada; na pesagem dos vasos, pą ra determinação da variação do armazenamento diārio de água do solo.

\subsection{Preparo do solo e adubiação}

Os solos foram primeiramente peneirados, utili zando-se para isto uma peneixa de $2 \mathrm{~mm}$ de diâmetro de malha, e submetidos a secagem ao ar até umidade constante, determinada gravimetricamente.

A adubação utilizada foi estabelecida, conforme recomendação de sistema de produção de cebola, para o estado de Santa Catarina (1982). A adubação preconizada foi de 5 a $10 \mathrm{~kg}$ de esterco de curral bem curtido, 60 gramas de fósforo, 30 gramas de potássio e 15 gramas de nitrogênio, por metro quadrado de ārea de sementeira. Utilizou-sé como fontes de nitrogênio, fósforo e potássio; urêia, superfosfato triplo e cloreto de potássio, respectivamente. Feito os respectivos câlculos, utilizou-se para cada vaso, 10 gramas da mistura de 
fertilizantes químicos e 500 gramas do fertilizante orgânico.

\subsection{Preparo dos vasos}

Foram utilizados vasos plásticos, com as dimen sões de $25 \mathrm{~cm}$ de diâmetro na sua parte superior e $24 \mathrm{~cm}$ de al tura, sendo perfurado o fundó dos mesmos, com uma broca de 10 nm cie diâmetro, em cinco pontos distribuídos de forma ordenada e equidistantes. Revestiu-se estas aberturas com manta de Bidim de $3 \mathrm{~mm}$ de espessura, com a finalidade de melhorar a drenagem.

Colocou-se $9,4 \mathrm{~kg}$ da mistura TRE e adubo orgâa nico em cada vaso, e adicionou-se 10 gramas do fertilizante quí mico, procedendo-se, logo em seguida, a incorporação do mesmo.

Em relação ao outro solo, houve o mesmo procedimento, porém com $10,0 \mathrm{~kg}$ da mistura $\mathrm{LVm}$ e adubo orgânico e 10 gramas do fertilizante químico. Determinou-se as umidades das misturas de TRE e LVm com adubo orgânico, cujos resul tados foram de $7,92 \%$ e $3,31 \%$ respectivamente.

A Tabela 2 mostra os pesos totais de cada vaso com os respectivos solos. 
Tabela 2. Peso total dos vasos sem umidade nos dois tipos de solo.

\begin{tabular}{lcccc}
\hline Solo & $\begin{array}{c}\text { Massa de } \\
\text { soloseco } \\
(\mathrm{g})\end{array}$ & $\begin{array}{c}\text { Massa do } \\
\text { adubo mineral } \\
(\mathrm{g})\end{array}$ & $\begin{array}{c}\text { Massa do } \\
\text { vaso } \\
(\mathrm{g})\end{array}$ & $\begin{array}{c}\text { Massa total } \\
\text { do vaso } \\
(\mathrm{g})\end{array}$ \\
\hline TRE & $8.710,1$ & 10,0 & 226,0 & $8.901,9$ \\
$\mathrm{LVm}$ & $9.679,6$ & 10,0 & 226,0 & $9.874,8$ \\
\hline
\end{tabular}

\subsection{Agua disponivel}

A āgua disponível foi calculada pela diferença, entre a capacidade máxima de retenção (Capacidade de Campo) e o Ponto de Murcha Permanente.

A Capacidade de Campo foi determinada pelas nor mas convencionais, isto é, saturou-se o solo e, após 5 dias foi verificado que não havia mais drenagem. Foram determina das as umidades de ambos os solos obtendo-se 2.2,6\% para O TRE e 11,5\% para o LVm. Estas umidades correspondem à tensão de 0,03 Mpa de acordo com as curvas de retenção (Figuras 2 e 3).

Qs Pontos de Murchamento Permanente foram determinados pelas curvas caracteristicas, tomando-se a umidade a 1,5 Mpa de tensão, cujos resultados foram 13,5 e 6,5\% para 0 TRE e LVm respectivamente. A Tabela 3 mostra os valores de água disponível para ambos os solos. 
T'abela 3. Teores de água no solo na capacidade de campo e pon to de murcha permanente em percentagem, com base em peso nos dois solos.

\begin{tabular}{lccc}
\hline Solo & C. Campo & PMP \\
& & $\frac{0}{6}$ & $\begin{array}{c}\text { A.D } \\
\frac{8}{6}\end{array}$ \\
\hline TRE & 22,6 & 13,5 & 9,1 \\
LVm & 11,5 & 6,5 & 5,0 \\
\hline
\end{tabular}

3.8. Delineamento experimental

o delineamento experimental constou de um esquema fatorial $2 \times 4$ constituindo 8 tratamentos, resultantes de dois tipos de solo, cada um submetido a quatro níveis de irrigação em função da āgua disponível, com 6 repetições, dis tribuídos inteiramente ao acaso, propiciando um total de 48 parcelas.

Tratamento 1 - Os solos eram irrigados, quando 10\% da ägua dis ponível era consumida;

Tratamento 2 - Os solos eram irrigados, quando 30\% da água dis ponivel era consumida;

Tratamento 3 - Os solos eram irrigados, cuando 50\% da água dis ponivel era consumida;

Tratamento. 4 - Os solos eram irrigados, quando $70 \%$ da ăgua dis ponivel era consumida. 
Estes tratamentos serão mencionados com 10\%, $30 \%, 50 \%$ e $70 \%$ de consumo de água disponível.

Pelos pesos secos determinados para ambos os so los e de acordo com os valores de Capacidade de Campo e Ponto de Murcha Permanente conhecidos, o controle da água de irriga ção foi conduzido por meio de pesagens diárias. A Tabela 4 mostra os valores calculados para o controle da irrigação.

\subsection{Cultivar $\underline{\text { e semeadura }}$}

A cultivar utilizada foi a Baia Periforme Pre- coce, bastante difundida nas regiões produtoras de cebola do estado de são paulo. O teste de germinação desse material foi realizado no laboratório de Análise de Sementes da ESALQ, obtendo-se uma porcentagem de geṛminação de 85\%.

A semeadura foi efetuada no dia 27 de junho de 1985, utilizando-se o processo manual a lanço, uma densidade de semeadura da ordem de $1,0 \mathrm{~kg}$ de sementes para cada 300 metros quadrados de sementeira. Feita a contagem, verificou se que, cada grama de semente continha aproximadamente 250 uni dades e, feitos os devidos cálculos, semeou-se 70 sementes por vaso. Procedeu-se a irrigação de todos os vasos um dia antes da semeadura. Após a semeadura, cobriu-se as sementes com aproximadamente $3 \mathrm{~mm}$ de terra peneirada e, com um pedaço de madeira, fiez-se a compactação para melhorar o contato da semente com o solo. 


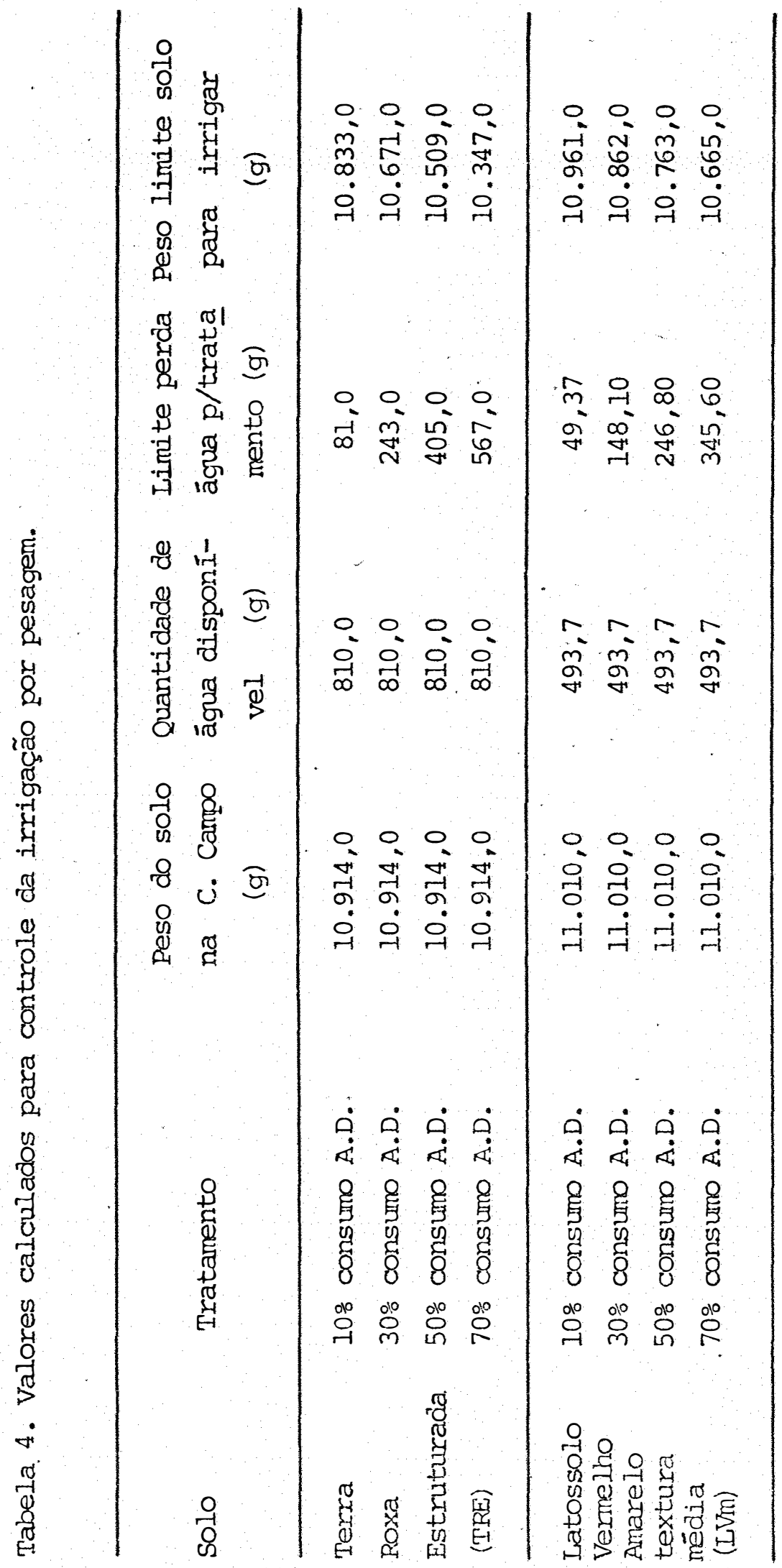




\subsection{Manejo}

O experimento foi mantido, durante os primeiros vinte dias, com umidade próxima a Capacidade de Campo, com a finalidade de permitir uma boa germinação e desenvolvimento inicial das mudas.

Durante os primeiros trinta dias da instalação do experimento, evitou-se a incidência direta do sol sobre as mudas, nas horas mais quentes do dia, utilizando-se para isto uma cobertura com tecido de algodão (Figura 4).

Com o objetivo de evitar que as águas das chuvas atingissem o experimento, utilizou-se uma cobertura de plástico transparente, fixada em uma estrutura de madeira. com este cuidado evitou-se que as chuvas ocorridas durante a condução do experimento, dificultasse o controle da água nos vasos (Figura 5).

\subsection{Tratos culturais.}

Para a manutenção de um bom nível de sanidade das mudas foram feitos tratamentos preventivos, com pulverizações alternadas, de sete em sete dias, utilizando-se dois tipos de fungicidas: o Benlate e o Manzate, nas dosagens, con forme as recomendações do fabricante. Não houve aparecimento de doenças, durante o período em que as mudas estiveram a 


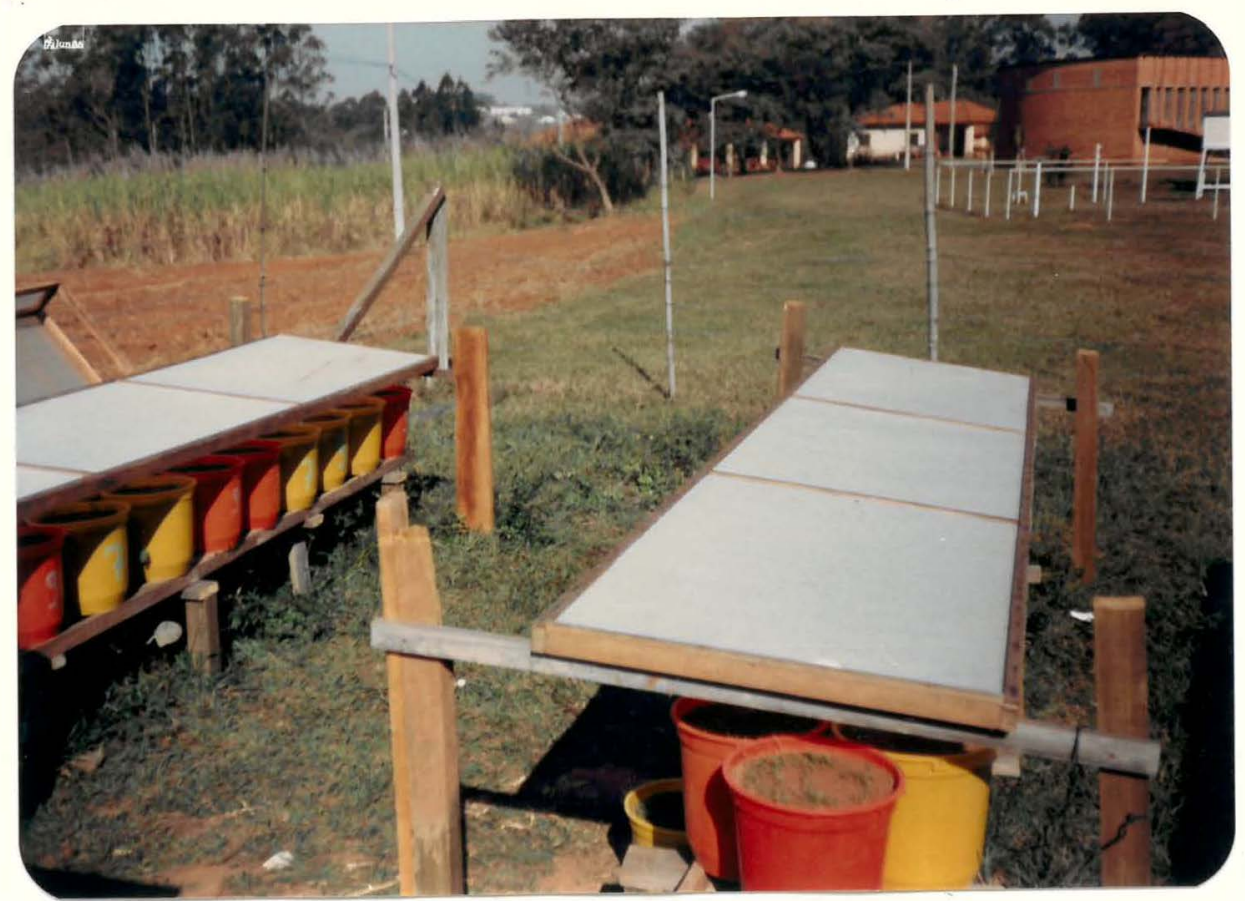

Figura 4. Cobertura do experimento com tecido de algodão.

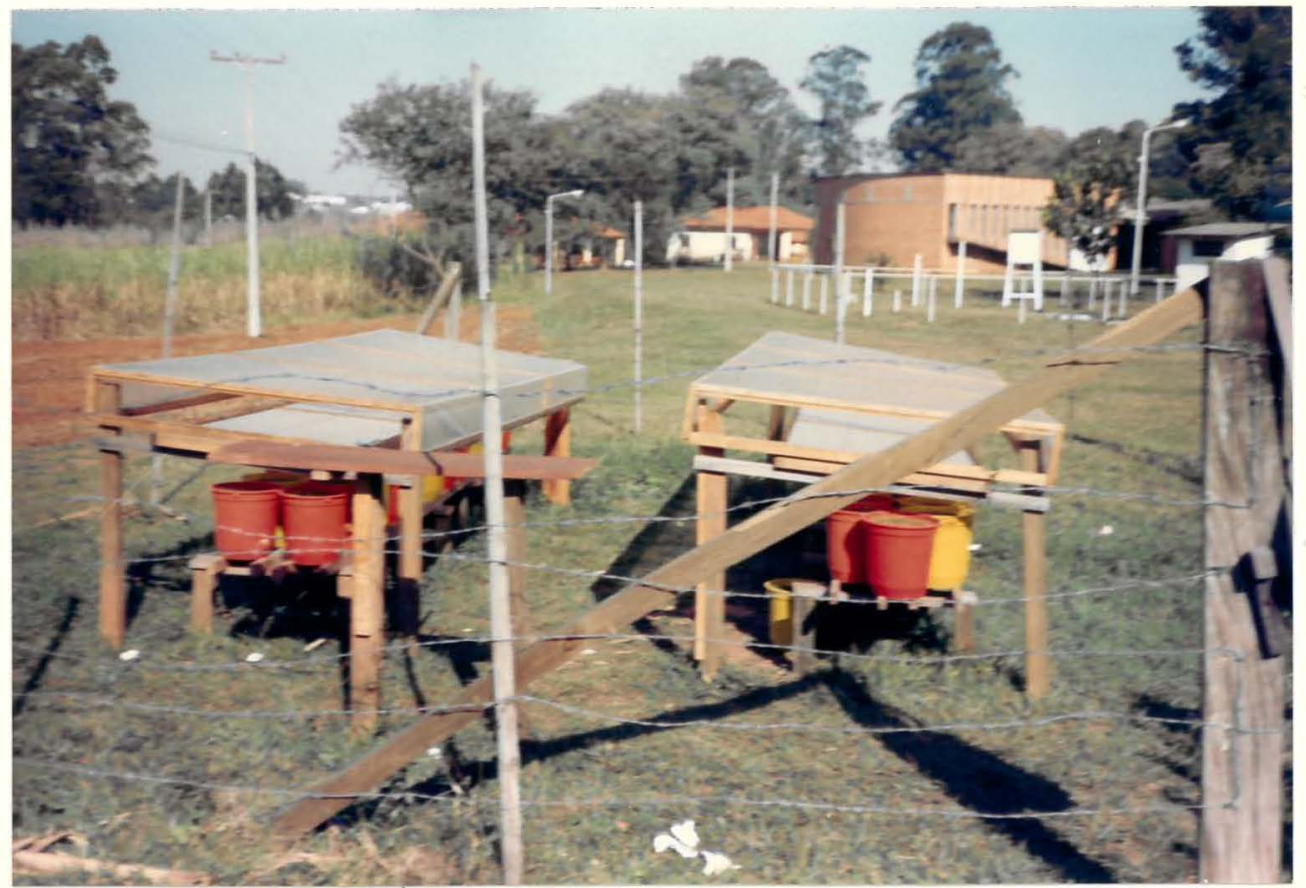

Figura 5. Cobertura do experimento com plástico transparente. 
campo; a não ser a ocorrência do Tombamento (Damping-off) na fase inicial, provocando uma redução de aproximadamente $40 \%$ no estande das mudas que foram conduzidas sobre $\bigcirc$ Latossolo Vermelho Amarelo (LVm). Em relação a TRE o ataque foi mui to pequeno e praticamente não prejudicou o estande final.

No controle às pragas, uma única pulverização com o inseticida Malatol $50 \mathrm{E}$, foi suficiente para eliminar as poucas pragas que ameaçavam provocar algum dano.

A incidência de ervas daninhas foi muito peque na; uma simples catação manual foi o suficiente para eliminar as poucas existentes.

\subsection{Controle da irrigação}

Vinte dias após a'semeadura, foi efetuada uma irrigação, com o objetivo de colocar todos os vasos na umidade de Capacidade de Campo, para então iniciar o controle da irrigação por pesagem. Diariamente, pesava-se todos os vasos (Figura 6) e verificava-se, conforme Tabela 4, da necessidade ou não de efetuar a irrigação.

Aos 43 dias após a germinação das sementes, o tratamento $10 \%$ de consumo de água disponível, exigia duas irrigações diārias, efetuadas a primeira pela manhã e a segunda à tarde, caso contrário, esse tratamento se igualaria ao tratamento imediatamente inferior. Este perícdo foi determinado efetuando se duas pesagens diariamente (manhã e tarde). 


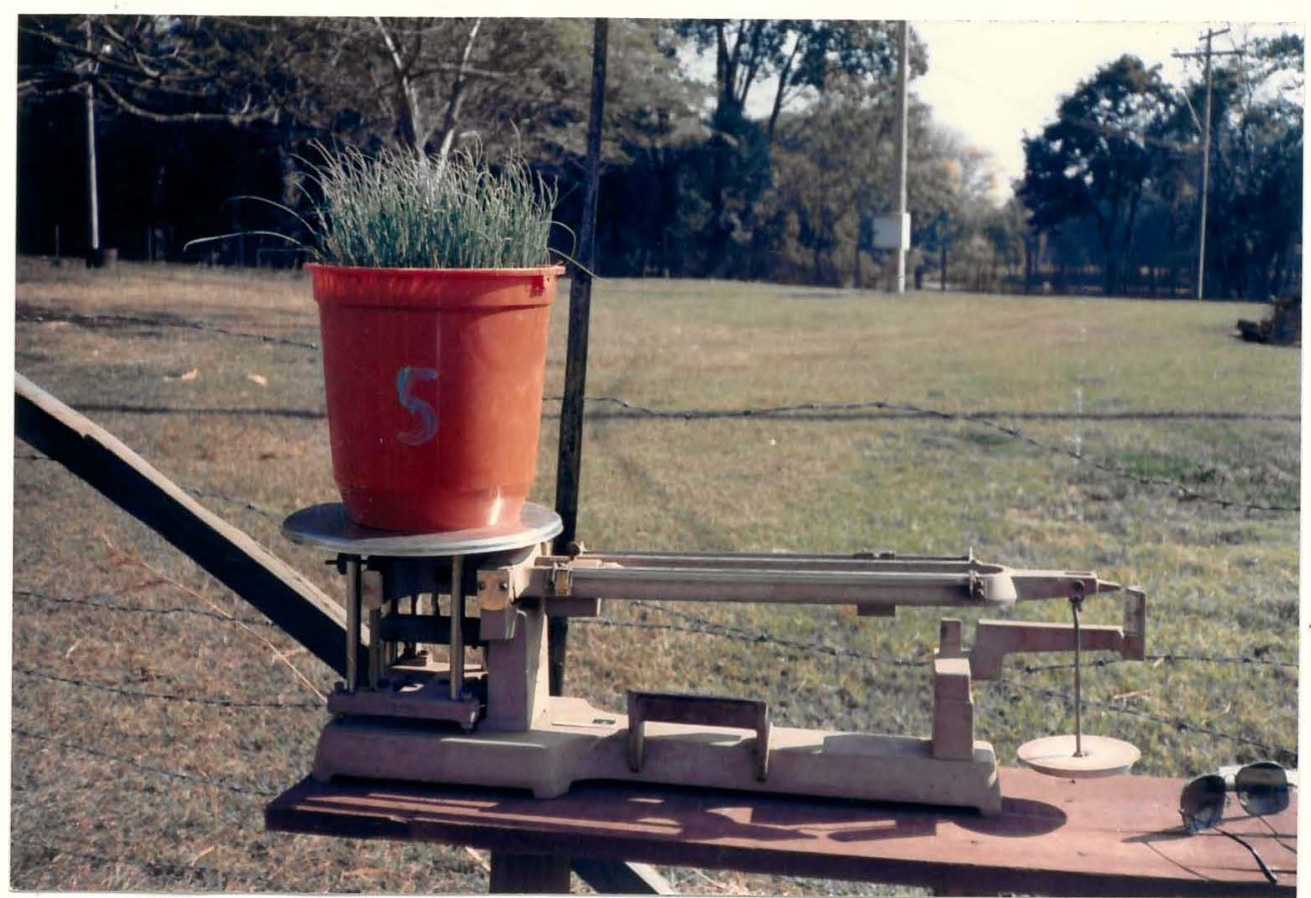

Figura 6. Pesagem dos vasos para o controle da irrigação.

A quantidade de āgua de irrigação era meçida com o auxílio de proveta e distribuída nos vasos com regador de crivo fino.

\subsection{Dados meteorológicos}

Os dados referentes a precipitação e evapotrans piração foram obtidos em pluviômetro e no tanque classe "A", instalados no Posto Meteorológico situado próximo a ārea expe rimental (Figura 7). 


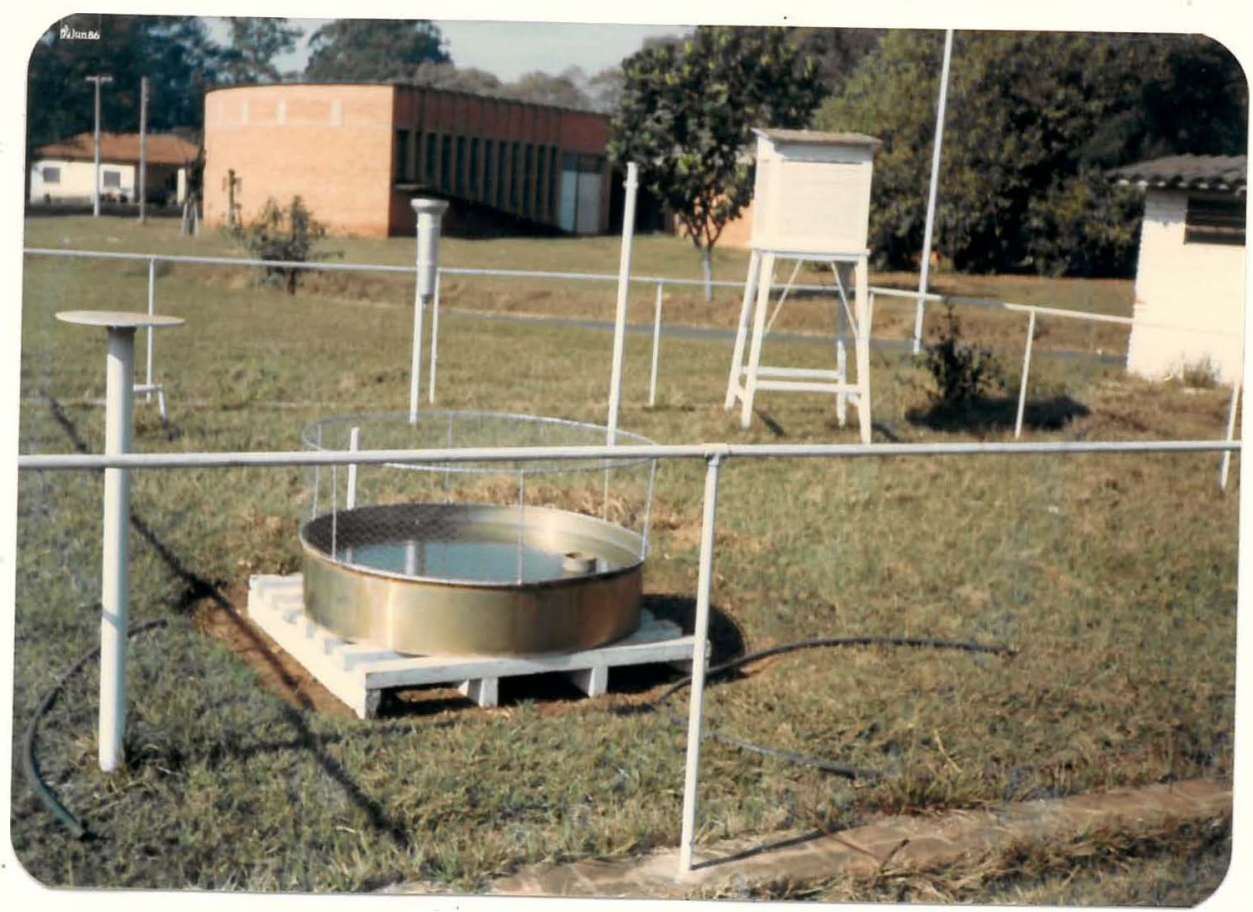

Figura 7. Posto Meteorológico.

Os dados referentes a velocidade do vento, tern peratura média e umidade relativa do ar, foram obtidos junto ao Posto Meteorológico do Departámento de Física e Meteorolo gia da ESALQ. Na Iabela 5 do Apêndice encontram-se os dados meteorológicos diārios.

\subsection{Biometria}

Proceảeu-se a mensuração das seguintes variāveis: 
- Diâmetro do pseudo-caule;

- Altura das mudas;

- Produção de matéria seca.

Para a determinação destas variáveis foram colhides aos sessenta dias após a semeadura quinze mudas, inteiramente ao acaso em cada repetição, procedendo-se a retirada de todas as raízes das mudas. Utili zando-se uma régua milimetrada, procedeu-se a medição das alturas de todas as mudas e, em seguida, a medição do diâmetro do pseudo-caule foi feita com o auxílio de um paquímetro. A matéria seca foi obtida pela secagem das plantas devidamente condicionadas em sacos de papel, em estufa a 559C.

3.16. Estimativa da evapotranspiração de referência, utilizando tanque classe "A"

Conforme roteiro proposto por VILLA NOVA \& OMET TO (1980), estima-se a evapotranspiração de referência (ETo) com o auxílio do coeficiente do tanque $(\mathrm{Kp})$, conforme expressão abaix̣:

$$
\mathrm{ET} O \mathrm{Kp} \times \mathrm{ECA}
$$

ETo - Evapotranspiração de referência èm mm/dia;

ECA - Evaporação lida no tanque classe "A" em $\mathrm{mm} / \mathrm{dia}$;

Kp - Coeficiente do tanque. 
O coeficiente Kp foi determinado em função da velocidade do vento, umidade relativa do ar e bordadura do tanque, com auxilio da Tabela 6 do Apêndice.

\subsection{Estimativa do coeficiente de cultura}

o coeficiente de Cultura (Kc) é a relação entre a Evapotranspiração Real (ETa) (sem limitação de umidade) e a Evapotranspiração de referência (ETO), observadas num período de tempo em relação a uma cultura qualquer.

$$
\mathrm{Kc}=\frac{\mathrm{ETa}}{\text { ETO }}
$$

Kc - Coeficiente da cultura;

ETa - Evapotranspiração Real média no perj̃odo $\mathrm{mm} / \mathrm{dia}$;

ETo - Evapotranspiração de referência média no período $-\mathrm{mm} / \mathrm{dia}$.

A Evapotranspiração Real, refere-se a evarıotrans piração de uma cuitura em condições qualquer de umidade do so lo, ocorrida num período de tempo. O valor da Eriá representa assim, a demanda ciimätica relativa aos quatro tratamentos utilizados, ou seja: 10, 30, 50 e 70\% de consumo de água disponivel pelas mudas de cebola. Para cada tipo de solo (TRE e $\mathrm{LV}$ V) e para cada tratamento foi calculado o Kc corresponden- 
te. Na Tabela 7 do Apêndice encontra-se as quantidades médias de água aplicadas a cada tratamento durante o período de controle da irrigação.

\subsection{Análise estatística}

Foram efetuadas análise de variância e de regressão linear, quadrática e cúbica dos cados observados.

Utilizou-se o teste de Tukey, a 1\% de probainilidade, em relação as três variáveis, para os dois tipos de solo e para a interação nível de água e solo.

Verificou-se tambēm a distribuição de frequên-cia em relação ao diâmetro do pseuão-caule utilizando-se seis classes de diâmetro.

\begin{tabular}{cc}
\hline Classe & $\begin{array}{c}\text { Diàme tro } \\
(\mathrm{mm})\end{array}$ \\
\hline 1 & $0,0-2,0$ \\
2 & $2,1-3,0$ \\
3 & $3,1-4,0$ \\
4 & $4,1-5,0$ \\
5 & $5,1-6,0$ \\
6 & $>6,0$ \\
\hline
\end{tabular}

A frequêencia foi determinada em função dos qua tro níveis de āgua disponível e analisada individualmente em cada solo. 
Esquema de Análise de Variância

\begin{tabular}{lc}
\hline Causa da variação & G.L. \\
\hline Solo & 1 \\
Niveis/Solo (TRE) & 3 \\
Níveis/Solo (LVm) & 3 \\
Residuo & 40 \\
\hline Total & 47 \\
\hline
\end{tabular}




\section{TRESULTADOSS E DISCUSSÃO}

A Tabela 8 do Apêndice mostra os valores médios obtidos, a partir de 15 mudas em cada tratamento, por re petição, em relação a altura, diâmetro do pseudo-caule e produção de matéria seca, das mudas de cebola por ocasião da colheita.

4.1. Efeito dos tratamentos na altura das mudas

A análise de variância das alturas das mudas apresentada na Tabela 9, mostrou um efeito significativo, ao nível de 1\% de probabilidade, dos solos e da interação dos níveis de água e solo.

A altura média das mudas obtidas no Latosso-.. Io Vermelho Amarelo ( $\mathrm{LVm}$ ) foi $28,59 \mathrm{~cm}$, enquanto na Terra Roxa Estruturada (TRE) foi de $27,15 \mathrm{~cm}$. A maior altura das mu- 
Tabela 9. Análise de variância da altura das mudas.

\begin{tabular}{lrrrrr}
\hline Causas da Variação & G.L. & SQ & QM & Valor F & Prob. F \\
\hline Solo & 1 & 24,800299 & 24,800299 & 11,1965 & $0,00214^{*}$ \\
Nível/Solo 1 & 3 & 90,725763 & 30,241921 & 13,6520 & $0,00003 * *$ \\
Nível/Solo 2 & 3 & 47,614162 & 15,884720 & 7,1708 & $0,00084 * *$ \\
Nível x Solo & 6 & 38,379926 & 23,063321 & 10,4114 & $0,00011^{* *}$ \\
Resĩduo & 40 & 88,607736 & 2,215193 & & \\
\hline Total & 47 & 251,787962 & & & \\
\hline
\end{tabular}

C. v. $=5,339 \%$

** Significativo ao nível de 1\% de probabilidade.

das no LVm pode ser atribuída a redução no estande das mudas, em virtude do ataque do "Damping-off", doença que provoca o tombamento das mudas de cebola. A menor densidade das mudas deve ter propicjado maior aeração, luminosidade, disponibjlidade de nutrientes e ägua, favorecendo um maior desenvol.vimen to das mudas.

o desdobramento da interação entre níveis de āgua e solo, conforme Tabela 10, mostrou que os tratamentos 10,30 e $50 \%$ de consumo de ăgua disponível, produziram mudas com altura superior, quando comparadas com aquelas produzidas sob a influência do tratamento $70 \%$ de consumo de ăgua disponível, em ambos os solos.

Mesmo não havendo diferença significativa, en- 
tre os três primeiros niveis de água disponível utilizados nos tratamentos, verificou-se que o tratamento $30 \%$ de consumo de água disponivel, foi superior aos demais no TRE. Já no LVm, a maior altura das mudas foi obtida quando $10 \%$ de água disponível foi consumida.

Altura das mudas $(\mathrm{cm})$

Tratamentos

TRE LVM

$10 \%$ consumo A.D.

27,671 a

29,686 a

$30 \%$ consumo A.D.

28,868 a

29,418 a

$50 \%$ consumo A.D.

27,418 a

29,208 a

$70 \%$ consumo A.D.

$23,851 b$

$26,165 \mathrm{~b}$

- Médias seguidas de letras distintas diferem entre si pejo teste de Tukey a lo de probabilidade.

O ajuste das médias da altura das mudas, pela equação de regressão, mostrou que os resultados tiveram um com portamento quadrático para os dois tipos de solo, cuja representação grăfica é mostrada na Figura 8 .

Observando-se as duas curvas verifica-se um com portamento semelhante para ambos os solos. A maior resposta aos nỉveis de água foi observada no LVm, como discutido an teriormente. A altura das inudas aumentou com o nível da ägua disponîvel até aproximadamente $30 \%$ de consumo no TRE, verifi 


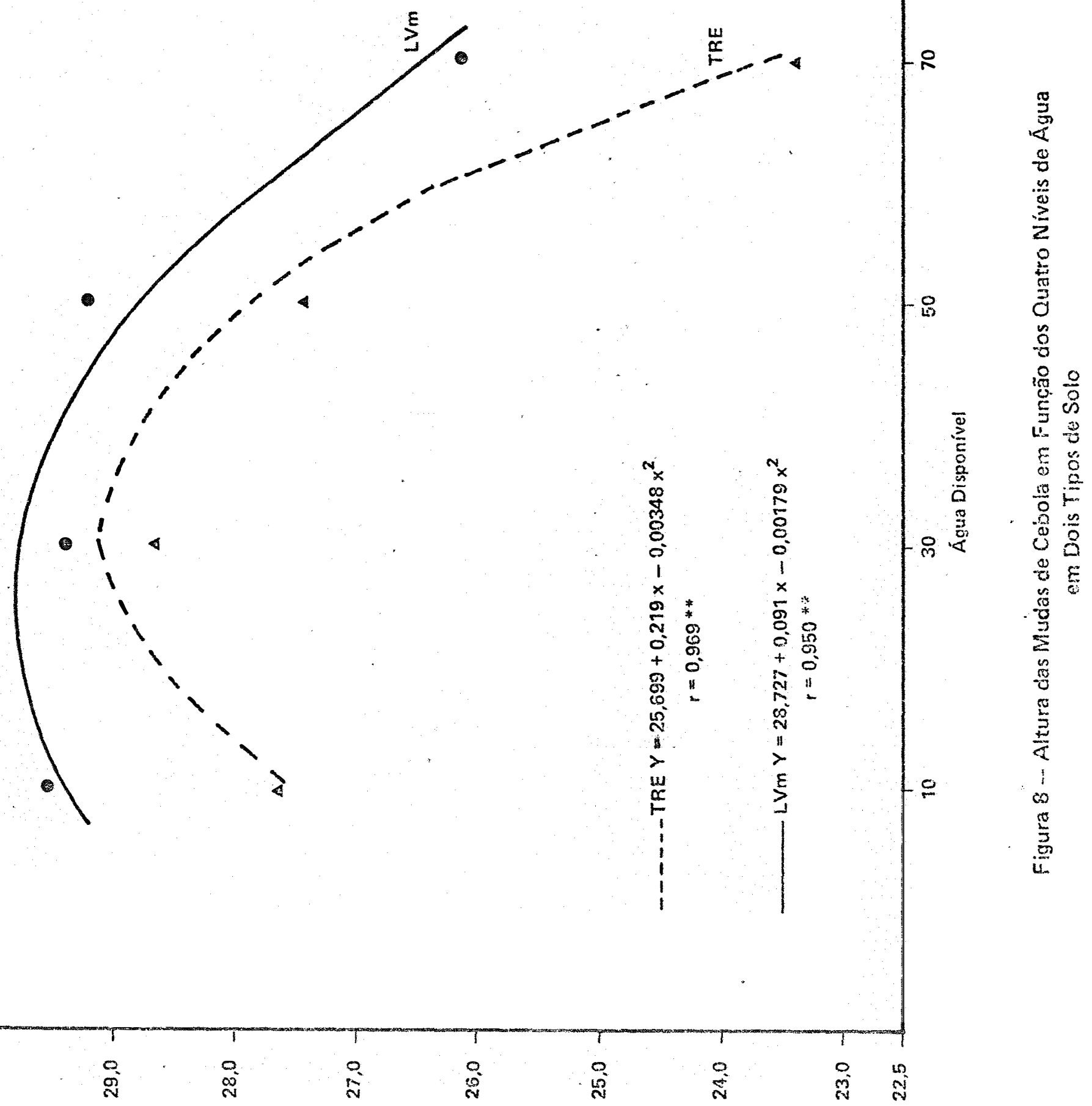


cando-se a partir daí um decréscimo no tamanho das mudas. Estes resultados mostram que a manutenção do teor de āgua do so 10, nos limites da capacidade de campo, não é ideal para a plan ta, isto pode sugerir, que a planta é afetada pelo arejamento do solo. No LVm tal fato não ocorreu, pois. o maior tamanho foi obtido no tratamento ao nível $10 \%$ de consumo de ăgua disponível, o que pode ser justificado que neste solo por ser mais arenoso, este nível de água não afeta o arejamento. Ressalta-se que, ao nível de' 30\% de consumo de àgua disponível, as mudas exigiam uma ūnica irrigação diāria, com exceção das duas primeiras semanas, onde houve intervalo de dois dias entre as irrigações.

4.2. Efeitos dos tratamentos na produção de matéria seca:

A anālise de variäncia da produção de matéria seca, apresentada na rabela 11 , mostrou que houve significân cia, ao nível de lo de probabilidade, dos solos e da intera ção dos níveis de ãgua e solo.

A produção média de matéria seca obtida no Latossolo Vermelho Amarelo ( $\mathrm{LVm}$ ) foi de 3,60 gramas, enguanto que a Terra Roxa Estruturada (TRE) foi de 2,24 gramas. A pro dução de matéria seca no LVm foi de $27,77 \%$ maior que na TRE.

o desdobramento da interção níveis de ãgua e solo, mostrado na Tabela 12, indica que os tratamentos 10,30 
e $50 \%$ de consumo de água disponivel, produziram maior quantidade de matéria seca, quando comparada com o tratamento $70 \%$ de consumo de água disponível.

Tabela 1l. Análise de variância da matéria seca.

\begin{tabular}{lrrrrr}
\hline Causa da Variação & G.L. & SQ & QM & Valor F & Prob. F \\
\hline Solo & 1 & 23,304192 & 22,304192 & 155,4360 & $0,00001 * *$ \\
Nível/Solo 1 & 3 & 6,125551 & 2,041850 & 14,2295 & $0,00002^{* *}$ \\
Nível/Solo 2 & 3 & 3,884582 & 1,294860 & 9,0238 & $0,00024 * *$ \\
Nível x Solo & 6 & 10,010133 & 1,668355 & 11,6266 & $0,00006 * *$ \\
Resíduo & 40 & 5,739775 & 0,143494 & & \\
\hline Total & 47 & 38,054100 & & & \\
\hline
\end{tabular}

$\mathrm{CV}=12,962 \%$

** Significativo ao nivel de 1\% de probabilidade.

Tabela 12. Valores médios da produção de matéria seca ( $g$ ) em relação aos 4 niveis de água disponivel nos dois tipos de solo.

\begin{tabular}{lll}
\hline \multirow{2}{*}{ Tratamentos } & \multicolumn{2}{c}{ Produção matéria seca $(\mathrm{g})$} \\
\cline { 2 - 3 } & \multicolumn{1}{c}{ TRE } & \multicolumn{1}{c}{ LVm } \\
\hline $10 \%$ consumo A.D. & $2,450 \mathrm{a}$ & $3,816 \mathrm{a}$ \\
$30 \%$ consumo A.D. & $2,775 \mathrm{a}$ & $3,933 \mathrm{a}$ \\
$50 \%$ consumo A.D. & $2,325 \mathrm{a}$ & $3,750 \mathrm{a}$ \\
$70 \%$ consumo A.D. & $1,143 \mathrm{~b}$ & $2,916 \mathrm{~b}$ \\
\hline
\end{tabular}

- Médias seguidas de letras distintas diferem entre si pelo teste de Tukey a lo de probabilidade. 
O comportamento na produção de matéria seca ve rificou-se de maneira semelhante, em ambos os solos, para os quatro níveis de água disponível.

- Mesmo não havendo diferença significativa, entre os três primeiros níveis de água disponível, observou - se que o tratamento que preconizava irrigar quando $30 \%$ de água disponível fosse consumida, apresentou maior procução de maté ria seca para ambos os solos. Pôde-se verificar que o efeito da redução da disponibilidade de água no solo, expressa em função dos níveis de água disponível 30 e $70 \%$ de consumo, reduziu a produção de matéria seca en 58,81\% no TRE e 25,85\% no $\mathrm{LVm}$.

O ajuste das médias da matéria seca pela equaçao de regressão mostrou que os resultados tiveram um comportamento quadrático, para os dois tipos de solo, cuja represen tação gráfica é mostrada na Figura $\ni$.

Observando as duas curvas, verificou-se um comportamento semelhante para ambos os solos, porém a maior resposta aos níveis de ăgua disponível, foi observada no LVm. A produção. de matéria seca aumentou até o consumo de $30 \%$ de água disponível, decrescendo a seguir até o tratamento $70 \%$ de consumo de água disponívej.

o éfeito do estresse hídrico na redução da matéria seca total, traduzido por um menor crescimento das mudas, encontrado no presente trabalho, está em concordânciacom alguns autores como KRAMER (1963), BEGG e TURNER (1976 e 1981). 


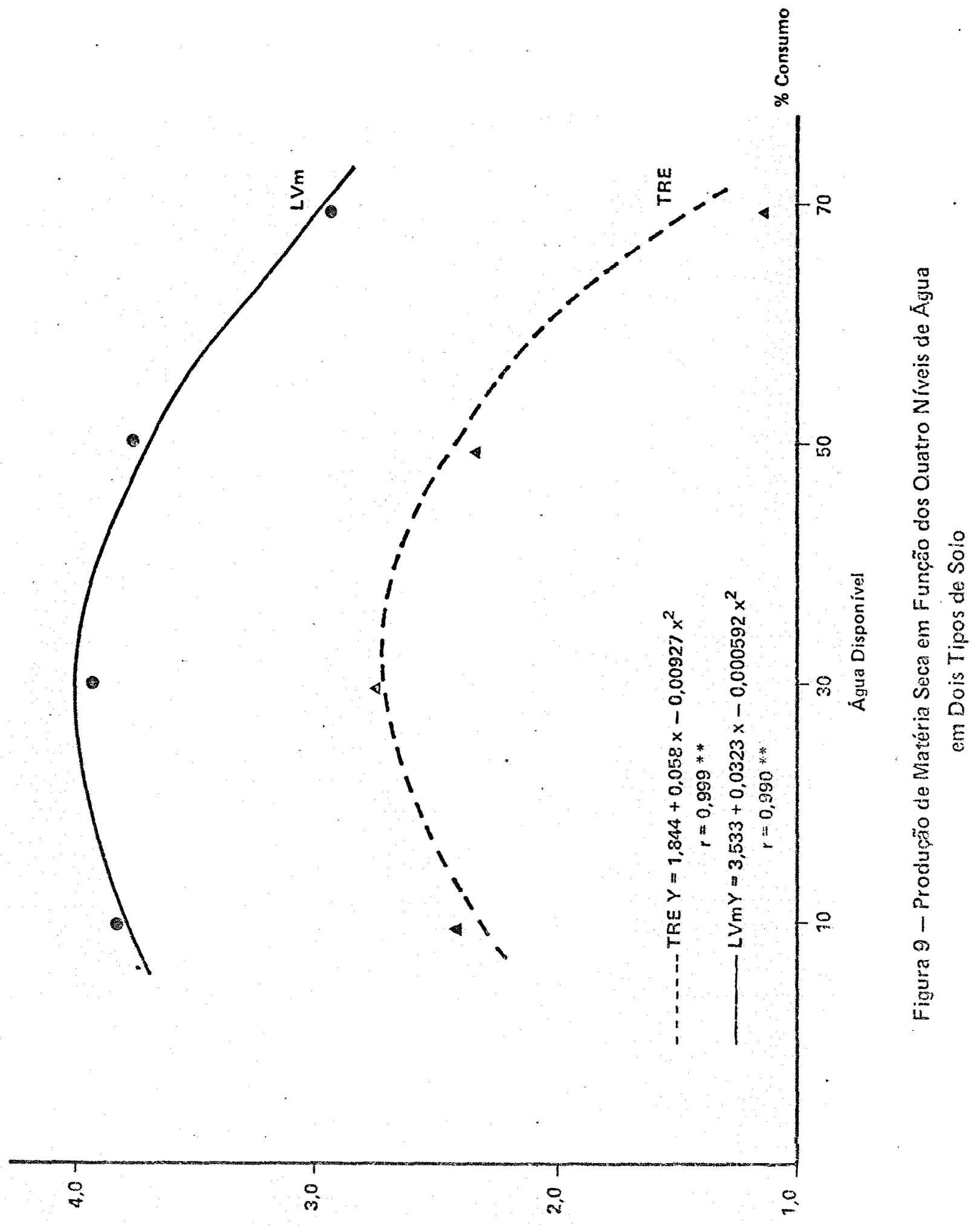

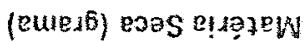


4.3. Efeito dos tratamentos do diâmetro no pseudo-caule

A análise de variância do diâmetro do pseudocaule, apresentada na Tabela 13 mostrou um efeito significati vo ao nivel de 1\% de probabilidade, para solos e para a interação dos níveis de ăgua e solo.

Tabela 13. Análise de variância do diâmetro do pseudo-caule.

\begin{tabular}{lcccccc}
\hline Causas da Variância & G.I. & SQ & QM & Valor F & Prob. F \\
\hline Solo & 1 & 7.386928 & 7,386928 & 167,6779 & $0,00001^{* *}$ \\
Nível/Solo 1 & 3 & 3,079912 & 1,026637 & 23,3039 & $0,00001^{* *}$ \\
Nível/Solo 2 & 3 & 3,733435 & 1,244478 & 28,2487 & $0,00001^{* *}$ \\
Nível x Solo & 6 & 6,813358 & 1,135558 & 25,7763 & $0,00001^{* *}$ \\
Resíduo & 40 & 1,762171 & 0,044054 & & \\
\hline
\end{tabular}

Total

$47 \quad 45,962448$

C.V. $=5,106 \%$

** Significativo ao nivel de lo de probabilidade.

No Latossolo Vermelho Amarelo ( $\mathrm{LVm})$ o diâmetro médio do pseudo-caule produzido foi significativamente superior (4,503 mm), quando comparado ao produzido na Terra Roxa Estruturada $(3,718 \mathrm{~mm})$.

A Tabela 14 apresenta os valores médios obtidos, no diâmetro do pseudo-caule, em relação aos quatro ní- 
veis de água disponível, nos dois tipos de solo. o desdobra mento da interação níveis de água e solos, indicou que os tra tamentos 10, 30 e 50\% de consumo de água disponível, produzi ram mudas com o diâmetro do pseudo-caule maior, quando comparadas com as mudas submetidas ao tratamento $70 \%$ de consumo de āgua disponível.

Tabela 14. Valores médios do diâmetro do pseudo-caule (mm) em relação aos 4 níveis de água disponível nois dois tipos de solo.

Diâmetro do pseuco-caule (mim)

Tratamentos

TRE

LVm

10\% consumo A.D.

3,945 a

4,685 a

$30 \%$ consumo A.D.

4,090 a

4,843 a

$50 \%$ consumo A.D.

3,690 a

4,653 a

$70 \%$ consumo A.D.

$3,150 \mathrm{~b}$

$3,831 \mathrm{~b}$

- Médias seguidas de letras distintas diferem entre si pelo teste de Tukey a. 1\% de probabilidade.

Como nas demais características vegetativas es tudadas, verificcu-se que o diâmetro do pseudo-caule teve com portamento semelhante para ambos os solos. Mesmo não haven-. do djferença significativa no diâmetro das rudas nos três prị meiros níveis de ăgua disponível utilizado, observou-se que o 
tratamento $30 \%$ de consumo de água disponível, produziu mudas com maior diâmetro em ambos os solos, conforme Tabela 14 .

Pela anālise de regressão, a equação quadrática foi a que melhor ajuste proporcionou para ambos os solos, cuja representação gráfica è mostrada na Figura 10.

observando as duas curvas, verificou-se um comportamento semelhante em ambos os solos.

A maior resposta aos níveis de água, na produção de mudas com maior diâmetro do pseudo-caule, foi obtida. no $L V m$.

O diâmetro do pseudo-caule das mudas de cebola, aumentou até o consumo de aproximadamente $30 \%$ de água dis ponível, verificando-se a partir daí um decréscimo no diâmetro.

Os resultados obtidos neste trabalho diferiram dos verificados por DEMATTE et alii. (1971), no qual estes pes quisadores não obtiveram diferença significativa em relação as três variáveis estudadas, quando utilizaram três níveis de água disponível 10,50 e 75\% de consumo.

Nos trabalhos realizados por $\operatorname{KLAR}(1972,1967)$, COSTA FILHO et alii. (1975), ABREU et alii. (1977) e SILVA e ARAOJO (1975), foram obtidos altas produções de bulbo de cebo la, quando mantinha--se o solo entre 75 e 100\% de água dispo-nível. Os resultados obtidos por estes autores são concorảan tes) aos conseguidos neste trabalho de produção de mudas, evidenciando que, tanto as mudas quanto os bulbos de cebola, respondem bem aos altos níveis de áqua aisponível do solo. 


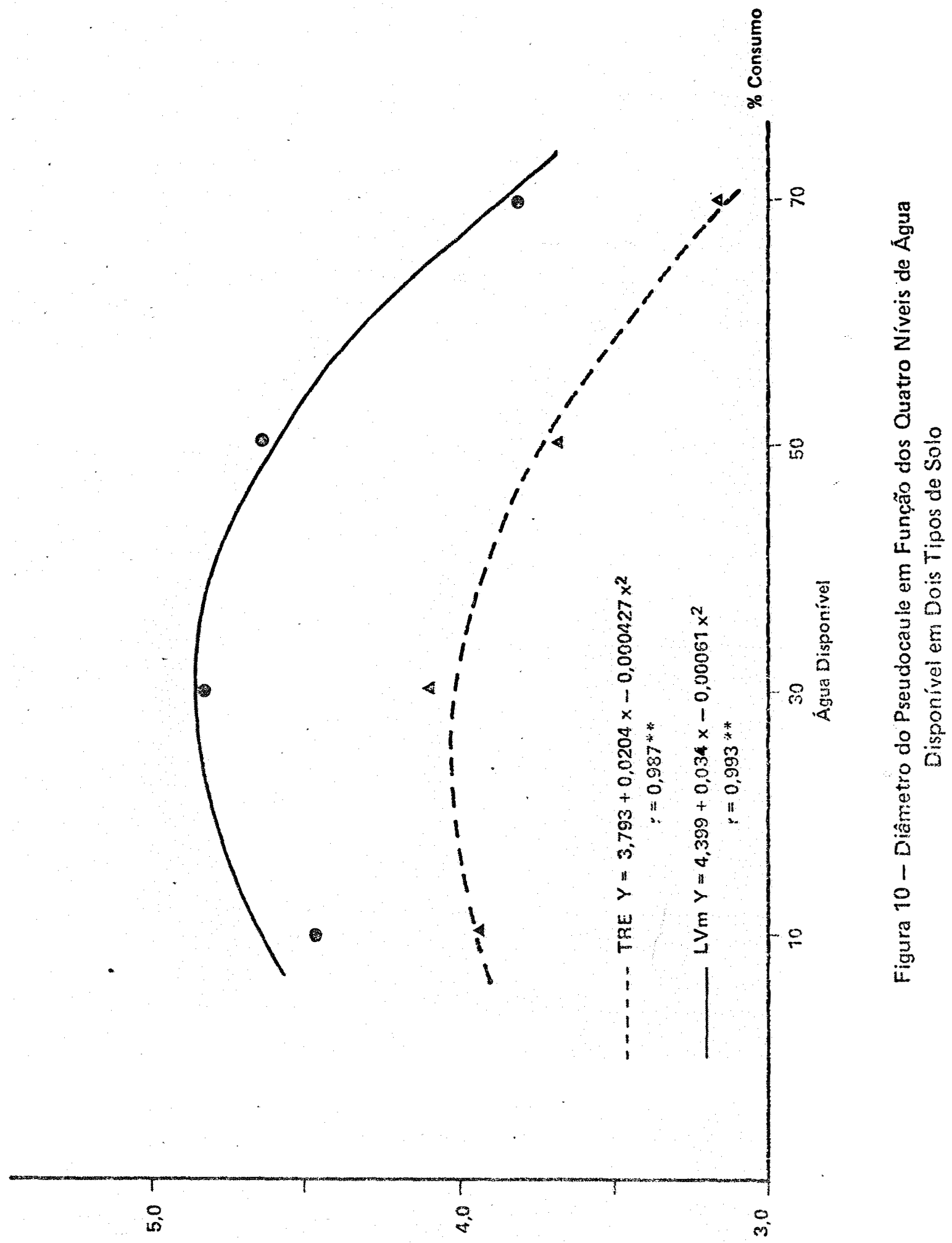

(unls) olnesopnosd op anowe! 


\section{3.i. Freqủência do diâmetro do pseudo-caule das mudas.}

Nas Figuras 11 e 12 são apresentadas as percen tagens da frequência dos diâmetros do pseudo-caule, resultantes da interação níveis de água e solo.

Verificou-se que na Terra Roxa Estruturada (TRE),

os tratamentos 10 e $30 \%$ de consumo de água disponível, mostra ram-se equivalentes quanto a frequência das mudas produzidas com o mesmo diâmetro, em termos percentuais. Ambos os tratamentos produziram mais de $90 \%$ das mudas com diâmetro superior a 3,1 mm. O tratamento $70 \%$ de consumo de água disponivel, foi o que produziu mudas de menor diâmetro, sendo que $45 \%$ do total produzido apresentaram diâmetro inferior a 3,0 mm.

A frequêencia de mudas com diâmetros maiores, foi superior no Latossolo Vermelho Amarelo ( $L V m$ ), enquanto na terra Roxa Estruturada (TRE) foi menor.

No LVm, o comportamento dos tratamentos $10 \mathrm{e}$ $30 \%$ de consumo de áqua disponível, quanto a percentagem de freqứência em relação ao diâmetro foi semelhante, e do total das mudas produzidas, 80\% obtiveram diâmetro superior a 4,1 $\mathrm{mm}$.

Os resultados da presente pesquisa na TRE, são concordantes com aqueles conseguidos por DEMATTE et alii (1971), que obtiveram produções significativas de mudas com diâmetro do pseudo-caule inferior a $3,0 \mathrm{~mm}$, no tratamento que 


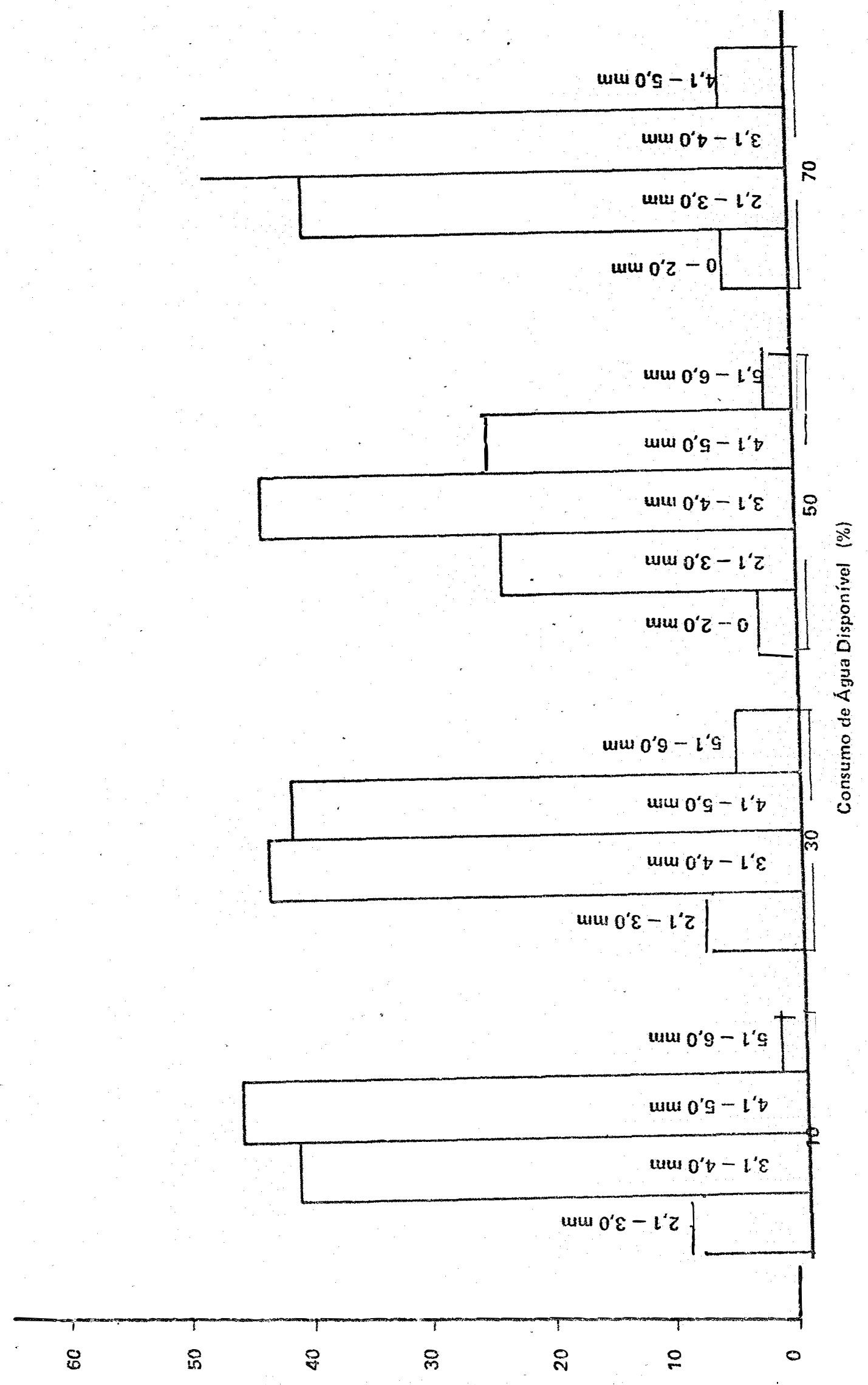

43.

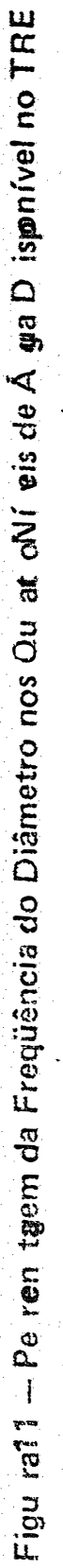

(\%) onguelo op elougnbas 


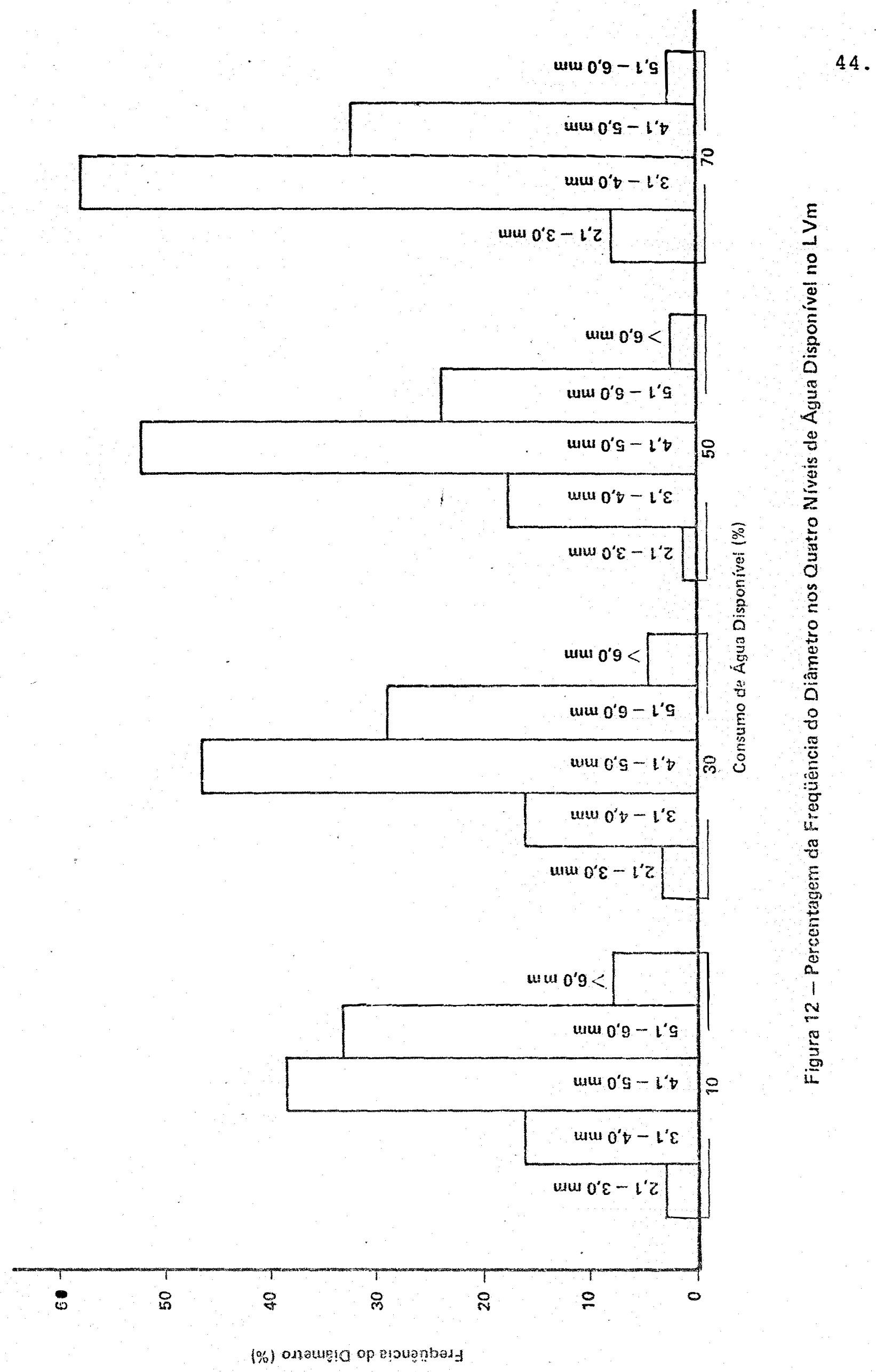


preconizava irrigar,quando $75 \%$ da água disponível do solo fos se consumida.

\subsection{Consumo de água}

A evapotranspiração de referência (ETo) foi es timada a partir dos dados da evaporação obtida no tanque clas se "A" (ECA), utilizando-se o coeficiente do tanque (Kp) conforme equação seguinte:

$$
\mathrm{ETO}=\mathrm{Kp} \times \mathrm{ECA}
$$

Atravēs das pesagens diárias dos vasos foi determinada a evapotranspiração real (ETa). Os valores diários de consumo de água, usados para o cálculo da ETa, estão apresen tados na Tabela 7 do Apêndice.

A quantidade mēdìa de água consumida, em mm/ dia, na interação níveis de àgua e solo está apresentada na Ta bela 15 .

Verifica-se que, a medida que decrescem os niveis de āgua disponível, diminui a quantidade de água gasta por dia, em ambos os solos.

Considerando irrigar, quando $30 \%$ da água disponível foi consumida, teremos um consumo médio de $242 \mathrm{~mm}$ de água durante o período de produção de mudas. 
Tabela 15. Valores médios em mm/dia, de ãgua consumida pelas mudas de cebola nos dois tipos de solo.

\begin{tabular}{lllll}
\hline & \multicolumn{3}{c}{ Tratamentos } \\
Solo & $10 \%$ & $30 \%$ & $50 \%$ & $70 \%$ \\
\cline { 2 - 5 } & 6,34 & 6,05 & 4,46 & 3,87 \\
TRE & 5,40 & 5,14 & 4,40 & 3,65 \\
\hline
\end{tabular}

4.5. Coeficiente da cultura

Com os dados da evapotranspiração de referência (ETO) e da evapotranspiração real (ETa) foi determinado - coeficiente da cultura ( $K c$ ) pela relação:

$$
\mathrm{Kc}=\frac{\mathrm{ETa}}{\mathrm{ETO}}
$$

Na Tabela 16 estão apresentados os valores dos coeficientes da cultura, porperíodo, para os diferentes niveis de água e solo.

A medida que aumenta-se, em função dos tratamentos, o consumo de água disponível, os valores encontrados do KC väo diminuinao. 


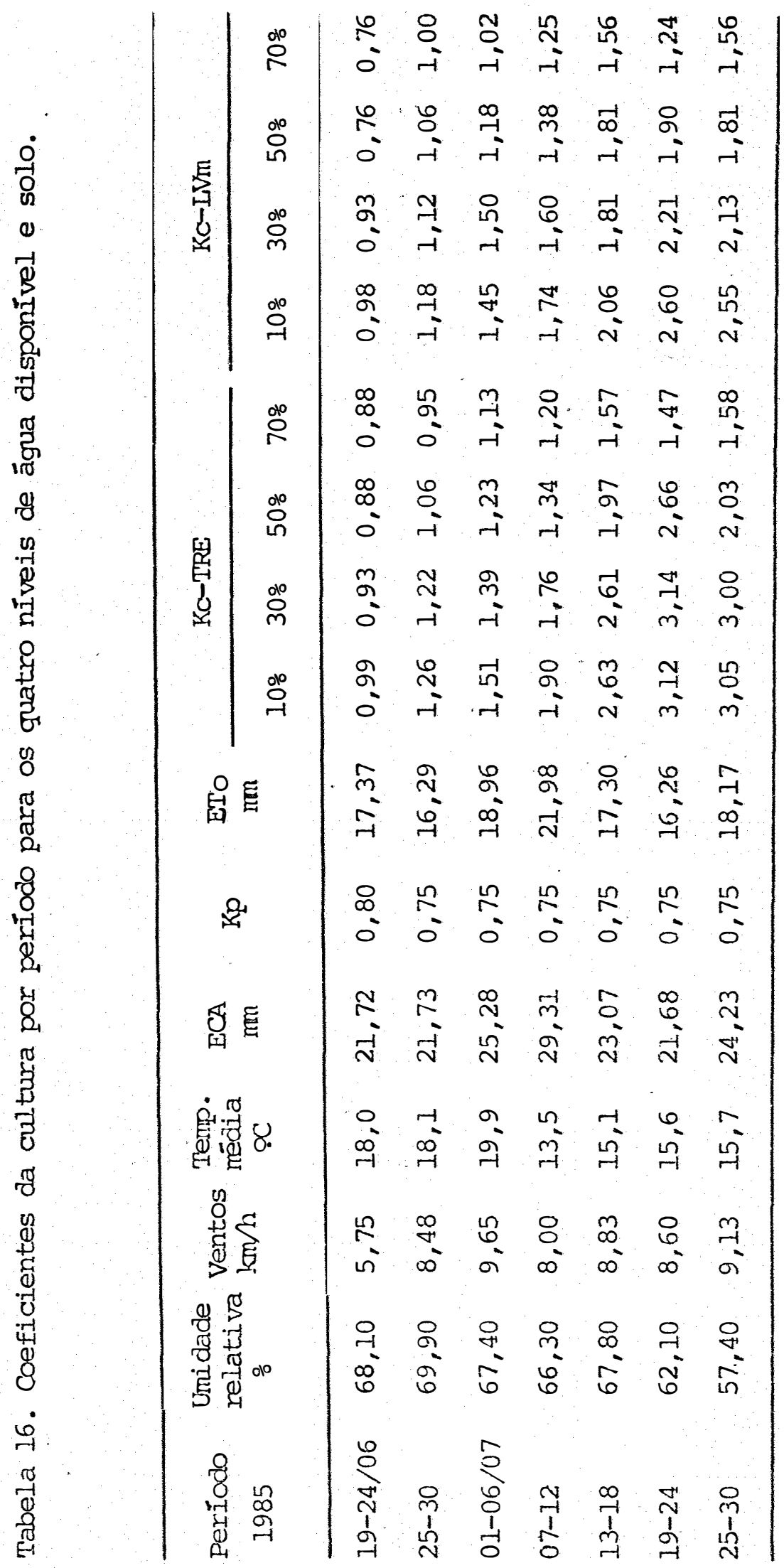


Observa-se pela Figura 13 que no TRE, os tratamentos 10 e $30 \%$ de consumo de āgua disponível, produziram os mesmos valores do coeficiente de cultura. Para os mesmos níveis de āgua disponível no LVm, os valores do Kc se distanciaram no final do período, sendo que o Kc relativo ao menor consumo de ãgua disponível teve maior valor. 


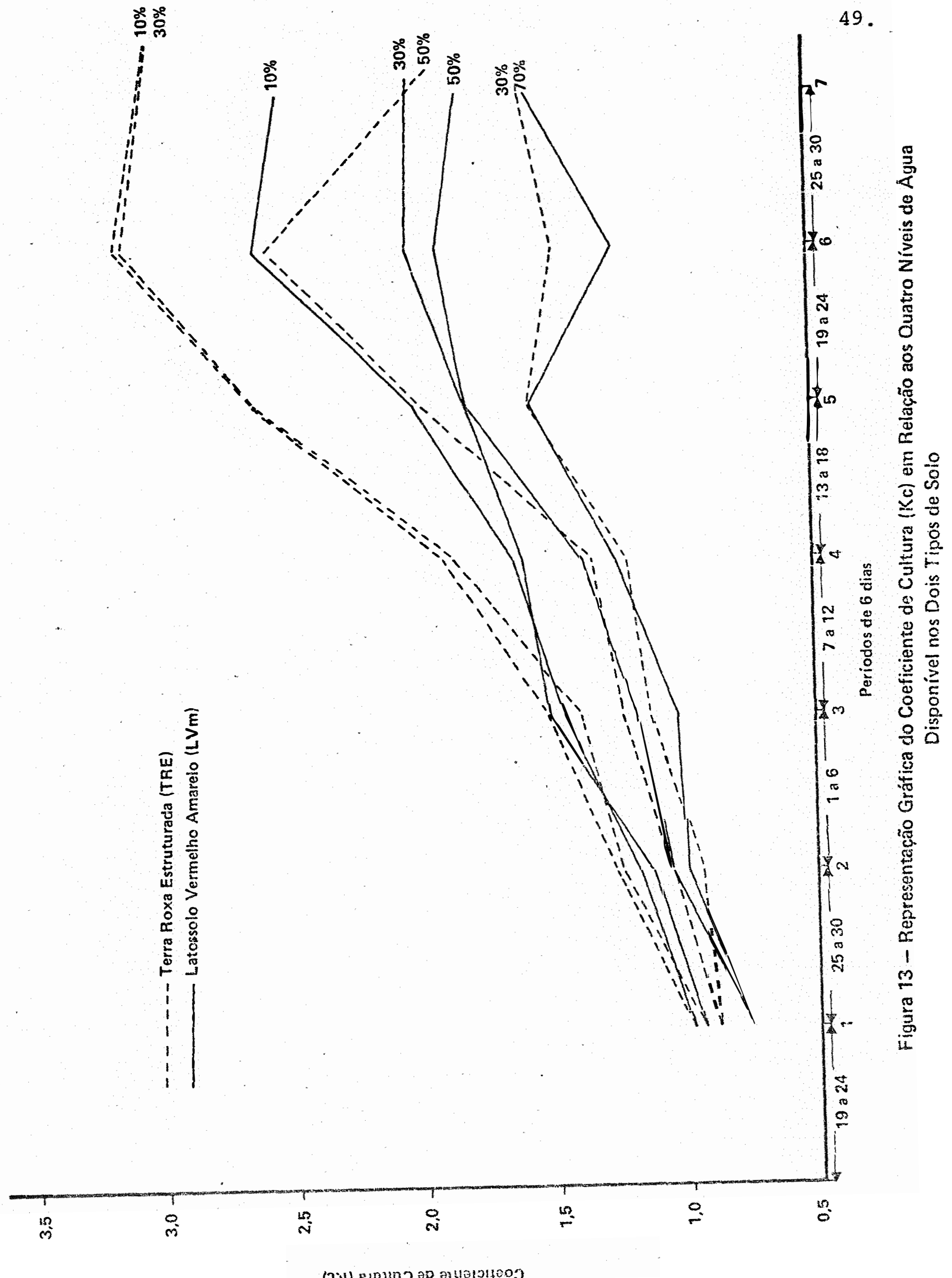




\section{CONCLUSÕES}

Em face dos resultados obtidos pode-se concluir que:

- As melhores mudas foram obtidas, quando irrí gadas até o limite de consumo de 30\% da água disponível, correspondenả a tensão de 0,044 MPa paca o TRE e 0,045 MPa para o LVm.

- As mudas produzidas no Latossolo Vermelino Amarelo (LVm), foram de melhor qualidade.

- Em ambos os solos, quando irrigados até o limite de consumo de $30 \%$ de água disponivel, $90 \%$ das mudas produzidas foram de diâmetro do pseudo-caule superior a 3,0 $\mathrm{mm}$.

- o consumo médio de água foi de 6,05 e 5,12 mm/dia, para a Terra Roxa Estruturada (TRE) e Latossolo Verme Iho Amarelo ( $\mathrm{LVm}$ ) respectivamente, para o tratamento de $30 \%$ de consumo de ăgua disponível, e os coefigientes da ciltura. 
variaram de 0,93 a 3,00 para o TRE e 0,93 a 2,13 para IVm, para as condições de clima e solos da presente pesquisa. 


\section{IITERATURA CITADA}

ABREU, T.A. dos S.; A.A. MILLAR; E.N. CHOUdHURY e M.M. CHOUDHURY, 1977. Produção de cebola sob diferentes regimes de irrigação. In: Anais do XVII Congresso da sociedade Brasi leira de Olericultura do Brasil. Juazeiro, 1: 53-52.

BEGG, J.E. e N.C. TURNER, 1976. Crop water deficits. Acivances in Agronomy. New York, 28: 161-234.

BRADY, N.C., 1967. Natureza e propriedade dos solos. Traduçao. Rio de Janeiro, USAID. 594 p.

BRASIL. Ministério da Agricuktura, 1978. Subsíaios ao plano nacional de produção e abastecimento de cebola. Brasilia, $79 \mathrm{p}$.

COSTA FILHO, J.F.; H.O. CARVALHO; F.O. SOUZA e. D. KDMIAN, 1977. Efeito de niveis de umidade na produção de cebola. In: Resumo do III seminārio de Irrigação e Drenagem. MINTER/DNOCS-ABID. Fortaleza, 3: 109-110. 
DEMATTE, J.B.I.; H.R. CAMPOS; T. IGUE e S. ALVES, 1974. Influência da irrigação na formação de mudas de cebola. Bragantia. Campinas, 33: 123-129.

DOORENBOS, J. e A.H. KASSAN, 1979. Efectos del àgua sobre el rendimento de los cultivos (Diego y Drenage). Boletim no 33. Roma, FAO, 179p.

FILGUEIRA, F., 1965. A influência da época, variedade, densidade de semeadura na produção de bulbinho de cebola. Viçosa, UFV, 33p. (Dissertação de Mestrado).

GONÇALVES, M.C., 1983. Alguns aspectos fisiológicos da bulbificação. In: Seminārio de Olericultura. Viçosa, $\underline{2}$ : 133.

HILL, D., 1970. Solo e água - Fenômenos e princíios físicos. Porto Alegre, Departamento de Solos da UFRGS. 231p.

JONES, H.A. E L.K. MANN, 1963. Onions and Their Allus. Iondon, Leonard Hill. 286p.

KLAR, A.E., 1967. Influência da umidade do solo sobre a cultura da cebola. Piracicaba, ESALQ/USP. 77p. (Tese de Dou toramento).

KLAR, A.E., 1972. Avaliação das necessidades hídricas das culturas de gladiolos e de cebola. Piracicaba, ESALQ/USP. $93 p$. (Dissertação de Mestrado).

KLAR, A.E., 1984. Agua no sistema solo - planta - atmosfera. São Paulo. Nobel. 408p. 
KRAMER, J.P., 1959. The role in the physiology of plants. Advance in Agronomy. New York, 11: 51-70.

KRAMER, J.P., 1959. Water stress and plant growth. Agronomy. Journal. Madison, 55: 31-35.

IIBARDI, P.L., 1984. Dinâmica da água no sistema solo - plan ta - atmosfera. Piracicaba, CENA/USP. $232 \mathrm{p}$.

MINAS GERAIS. Informe Agropecuärio, 1980. Cebola Auto-sufi. ciência e Normalização do Abastecimento. Belo Horizonte, 6: $2-11$.

PAES, C.A.; H.S. PINTO; R.R. ALFONSI $\cong$ A.A. ORTOLANI, 1974. Clima do Estado de São PauIo. In: SAEESP - IAC. Zoneanento, Agrícola do Estado de são Paulo, vol. 1.

RANZANI, G.; O. FREIRE e T. KINJO, 1966. Carta de solos do Município de Piracicaba. Centro de Estudos de Solos-ESAL/ USP. Piracicaba. 85p.

REICHARDT, K.A., 1978. A água na Produção Agrícola. São Paulo, McGraw-Hill. 115p.

RESS, A.R., 1972. The growth oI buls applied aspects of the physiology of ornamental bulbous crop plants. Academic Press. London, 311p.

SCARDUA, R., 1984. Irrigacão. Piracicaba. Centro Acadêmico "Luiz de Queiroz". 198p.

SILVA, J.F.; R.F. SILVA E J.J.V. RODRJGUES, 1971. Efeito do tamanho e poda de múas no rendimento da cebola. Revista CERES. Viçosa, 18: 418-429. 
SILVA, J.F. e J.T. ARAUJO, 1977. Irrigação da cebola. In: Re sumo do III Seminārio de Irrigação e Drenagem, MINTER/ DNOCS-ABID. Fortaleza, 3: 113-119.

SILVA, J.F. e J.T. ARAOJO, 1977. Irrigação da cebola. Boletim Técnico do DNOCS. Fortaleza, 35: 37-50.

SILVA, N.F., 1983. Influência do fotoperíodo sobre a cultura da cebola. In: Seminärio de Olericultura. Viçosa, 9: 107-149.

SOIL SURVEY STAFF, 1975. Soil Taxonomy. Agric. Handbook no 436. USDA-US Government Printing Office, Washington, DC.

STEER, B.T., 1980. The role of night temperature in the bulbing of onion. Journal of Agriculture Research. Austra lian, 31: 519-523.

TEN CATEN, R. e T. LUCIA, 1982. Cultura da cebola no Rio Grande do Sul. Porto Alegre, EMATER/RS. 93p.

TORRES, C.B., 1951. A influência do fotoperíodo na formação de bulbo nas variedades riograndense de cebola. Revista AGRO. Pelotas, 4: $219-234$.

VILLA NOVA, N.A. e OMETO, J.C., 1980. Evapotranspiração e evaporação. Departamento de Física e Meteorologia, Piraci caba, ESALQ/USP. 40p. (Apostila).

VIzzotTo,·V.J., 1984. Efeito do tamanho da muda e ảa época de transplante sobre a produção de bulbos comerciais de ce bola. Pelotas, UfPEL. 58p. (Dissertação de Mestrado).

YoKoyAMA, S., 1976. Comportamento de população decebola baia periforme com relação à época e técnica de cultivo. Piracicaba, ESALQ/USP. 60p. (Dissertação de Mestrado). 
A $E \underline{I I I} E$ 
Tabela 5. Dados meteorológicos diärios.

\begin{tabular}{|c|c|c|c|c|c|}
\hline Data & $\begin{array}{l}\text { Precipi } \\
\text { taçâo }\end{array}$ & $\begin{array}{c}\text { Evaporaçäo } \\
\text { Classe "A" } \\
\text { mm }\end{array}$ & $\begin{array}{c}\text { Ventos } \\
\mathrm{m} / \mathrm{s}\end{array}$ & $\begin{array}{c}\text { Temperatura } \\
\text { média } \\
\text { ฯc }\end{array}$ & $\begin{array}{l}\text { Umidade } \\
\text { relativa } \\
\frac{\%}{0}\end{array}$ \\
\hline $17 / 06 / 85$ & & 4,08 & $9,0$. & 19,0 & 74,6 \\
\hline & & 2,33 & 7,9 & 17,4 & 74,2 \\
\hline 19 & & 3,14 & 4,0 & 37,5 & 73,2 \\
\hline 20 & & 4,21 & 3,0 & 37,5 & 65,5 \\
\hline 21 & & 3,42 & 4,0 & $28,0^{\circ}$ & 66,5 \\
\hline 22 & & 2,65 & 5,2 & 18,6 & 58,0 \\
\hline 23 & & 3,45 & 2,0 & 19,0 & 71,3 \\
\hline 24 & & 4,85 & 8,0 & 18,3 & 72,9 \\
\hline 25 & & 3,04 & 7,0 & 19,1 & 78,9 \\
\hline 26 & & 2,78 & 2,0 & 17,8 & 77,0 \\
\hline 2.7 & & 3,25 & 3,0 & 18,0 & 80,7 \\
\hline 28 & & 4,82 & 3,0 & 17,2 & 70,7 \\
\hline 29 & & 2,61 & 12,1 & 18,3 & 40,0 \\
\hline 30 & & 5,23 & 8,2 & 19,5 & 59,5 \\
\hline $01 . / 07$ & & 4,51 & 5,3 & 19,7 & 71,0 \\
\hline 02 & $\therefore$ & 5,54 & 8,0 & 19,2 & 71,9 \\
\hline 03 & & 3,86 & 10,5 & 20,7 & 59,3 \\
\hline 04 & & 4,82 & $.21,7$ & 19,4 & 57,0 \\
\hline 05 & 0,1 & 3,86 & 10,5 & 20,7 & 59,3 \\
\hline 06 & 1,4 & 3,15 & 14,2 & $2 i, 0$ & 85,7 \\
\hline 07 & -1. & 3,40 & 4,3 & 14,3 & 66,5 \\
\hline 08 & & 5,71 & 3,0 & 19,6 & 64,9 \\
\hline 09 & & 5,02 & 5,7 & 13,7 & 72,6 \\
\hline $10^{\circ}$ & & 4,14 & 13,1 & 14,5 & 56,8 \\
\hline 11 & & 3,95 & 13,6 & 16,5 & 69,5 \\
\hline 12 & & 5,04 & 8,0 & 11,5 & 67,4 \\
\hline 13 & & 5,45 & 9,0 & 14,4 & 64,4 \\
\hline 14 & & 1,39 & 7,6 & 13,9 & 67,2 \\
\hline 15 & & 3,66 & 7,2 & 15,2 & 79,9 \\
\hline 16 & & 5,16 & 9,8 & $15 ; 5$ & 68,1 \\
\hline 17 & . & 4,00 & 9,2 & 16,0 & 65,4 \\
\hline 18 & 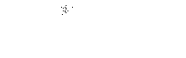 & 5,00 & 9,4 & 15,6 & 62,0 \\
\hline 19 & & 3,86 & 3,0 & 15,5 & 60,1 \\
\hline 20 & & 3,26 & 6,5 & 14,7 & 62,9 \\
\hline $2 I$ & & 4,14 & 6,3 & 15,0 & 55,9 \\
\hline 22 & 2,6 & 5,10 & 9,4 & 15,9 & 62,6 \\
\hline 23 & 5,2 & 3,54 & 9,0 & 16,6 & 67,5 \\
\hline 24 & & 2,09 & 8,0 & 16,1 & 64,6 \\
\hline 25 & & 3,57 & 5,9 & 14,8 & 64,5 \\
\hline 26 & & 3,10 & 3,8 & 15,1 & 60,4 \\
\hline 27 & & 5,13 & 10,0 & 14,5 & 59,1 \\
\hline 28 & 1,0 & 3,29 & 10,1 & 34,8 & 53,1 \\
\hline 29 & & $2, \bullet 6$ & 4,0 & 16,7 & 53,2 \\
\hline 30 & & 6,30 & 6,5 & 18,7 & 54,3 \\
\hline
\end{tabular}


Tabela 6. Valores do coeficiente de conversäo do tanque classe "A" (Kp), para a estimativa da evapotranspiração de referência (ENo) .

Exposiçä̀ A:

Tanoue circundado por grama

\begin{tabular}{|c|c|}
\hline $\begin{array}{l}\text { UR? } \\
\text { (média) }\end{array}$ & \\
\hline $\begin{array}{l}\text { Vento } \\
\text { (I Km/cia) }\end{array}$ & $\begin{array}{c}\text { Posição } \\
\text { do tanque } \\
d(m)^{*}\end{array}$ \\
\hline
\end{tabular}

Baixa Média Alta $<40 \% \quad 40-70 \%>70 \%$
Exposicão B

Tanque circundiado por solo nu

Baixa Media Alta

$<40 \div \quad 10-70 \%>70 \%$

\begin{tabular}{|c|c|c|c|c|c|c|c|c|}
\hline & 0 & 0,55 & 0,65 & 0,75 & 0 & 0,70 & 0,80 & 0,85 \\
\hline Ieve & 10 & 0,65 & 0,75 & 0,85 & 10 & 0,60 & 0,70 & 0,80 \\
\hline \multirow[t]{3}{*}{$<175$} & .200 & 0,70 & 0,80 & 0,85 & 300 & 0,55 & 0,65 & 0,75 \\
\hline & 1000 & 0,75 & 0,85 & 0,85 & 1000 & 0,50 & 0,60 & 0,70 \\
\hline & 0 & 0,50 & 0,60 & 0,75 & 0 & 0,65 & 0,75 & 0,80 \\
\hline Mioderado & 10 & 0,60 & 0,70 & 0,75 & 10 & 0,55 & 0,65 & 0,70 \\
\hline \multirow[t]{3}{*}{$175-425$} & 100 & 0,65 & 0,75 & 0,80 & 100 & 0,50 & 0,60 & 0,65 \\
\hline & 1000 & 0,70 & 0,80 & 0,80 & 200 & 0,45 & 0,55 & 0,60 \\
\hline & 0 & 0,45 & 0,50 & 0,60 & 0 & 0,60 & 0,65 & 0.70 \\
\hline Forte & 10 & 0,55 & 0,60 & 0,65 & 10 & 0,50 & 0,55 & 0,75 \\
\hline \multirow[t]{3}{*}{$425-600$} & 100 & 0,60 & 0,65 & 0,75 & 100 & 0,45 & 0,50 & 0,60 \\
\hline & 1000 & 0,65 & 0,70 & 0,75 & 1000 & 0,40 & 0.45 & 0.55 \\
\hline & 0 & 0,40 & 0,45 & 0,50 & 0 & 0,50 & 0,60 & 0,65 \\
\hline \multirow{3}{*}{$\begin{array}{l}\text { Muito forte } \\
>700\end{array}$} & 10 & 0,45 & 0,55 & 0,60 & 10 & 0,45 & 0,50 & 0,55 \\
\hline & 100 & 0,50 & 0,60 & 0,65 & 100 & 0,10 & 0,45 & 0,50 \\
\hline & 1000 & 0,55 & 0,60 & 0,65 & 1000 & 0,35 & 0,40 & 0.25 \\
\hline
\end{tabular}

- Transcrit • de "Crop Water Raquirements", DCORENBOS e KASSAM (1979). Nota: Para extensas áreas de solo nu, reduzir os valores de Kp de $20 \%$ em condições de alta temperatura e vento forte e de 5 a $10 \%$, em condiçöes de moderada temperatura, vento e umidade.

$\alpha=$ menor distância (expressa em retrosi), do centro do tanque ao Iimite da bordadura (grama ou solo nu) . 
Tabela 7. Volume de ägua aplicad em mililitro por tratamento. Texra Roxa Estruturada (TRE)

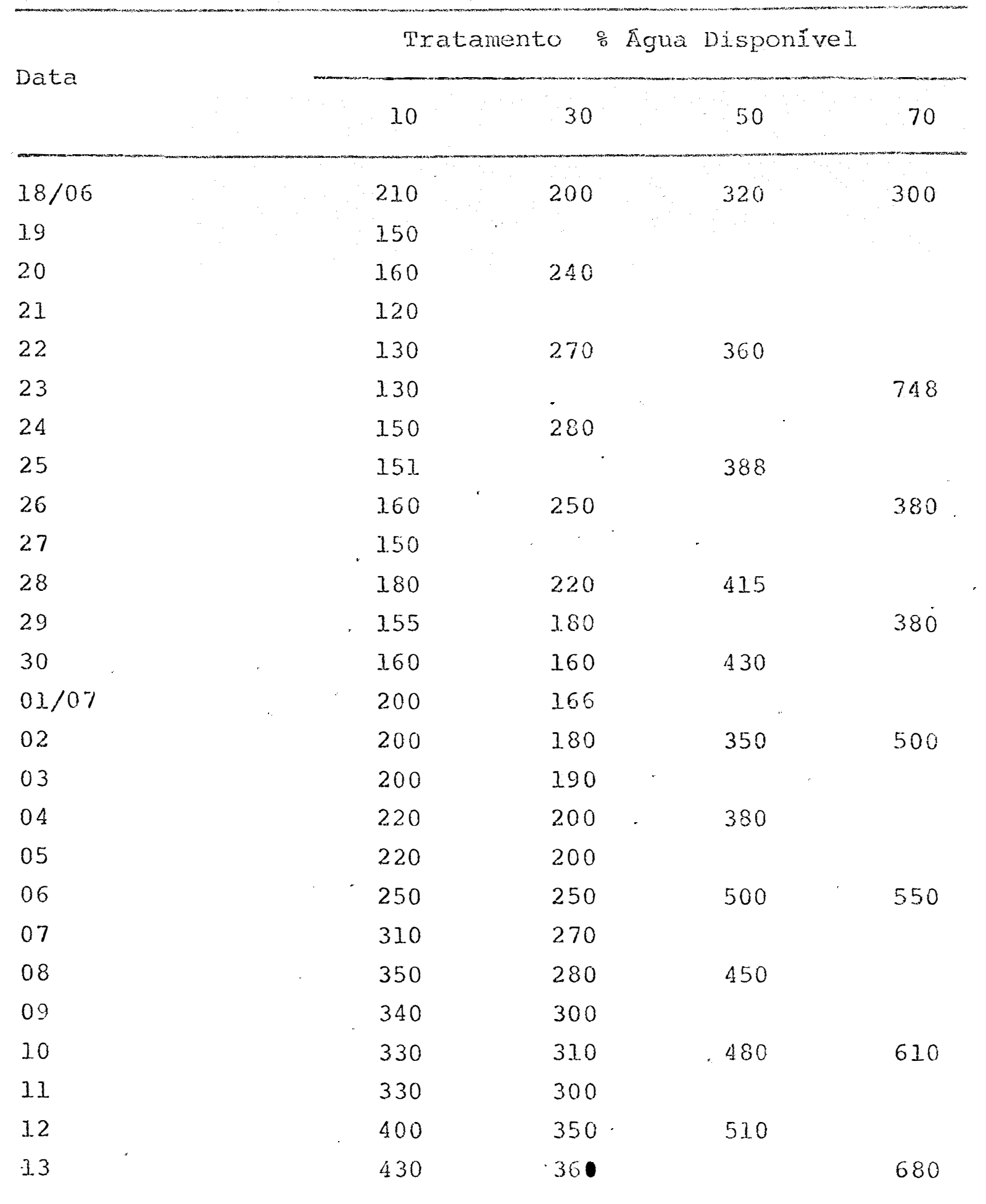


Tabela 7. Continuação.

\begin{tabular}{|c|c|c|c|c|c|c|c|}
\hline \multirow{2}{*}{ Data } & & \multicolumn{3}{|c|}{ Tratamento } & \multirow{2}{*}{\multicolumn{2}{|c|}{$\frac{\% \text { Ägua Disponivej }}{50}$}} & \multirow[b]{2}{*}{70} \\
\hline & & 10 & & 30 & & & \\
\hline $14 / 07$ & & 280 & & 250 & & 520 & \\
\hline 15 & & 320 & & 3.10 & & & 580 \\
\hline 16 & & 360 & & 400 & & 500 & \\
\hline 17 & & 415 & & 42,5 & & & \\
\hline 18 & & 500 & & 510 & & 650 & 755 \\
\hline 19 & & 360 & & 320 & & & \\
\hline 20 & & 386 & & 435 & & 540 & \\
\hline 21 & & 375 & & 420 & & & 586 \\
\hline 22 & & 463 & & 490 & & 680 & \\
\hline 23 & & 486 & & 420 & & 400 & 590 \\
\hline 24 & & 380 & & 360 & & & \\
\hline 25 & & 398 & & 380 & & 510 & \\
\hline 26 & & 435 & & 430 & & . & 640 \\
\hline 27 & & 510 & & 465 & & 633 & \\
\hline 28 & & 405 & & 445 & & & \\
\hline 29 & & 450 & & 420 & & 590 & 780 \\
\hline 30 & & 445 & & 415 & & & \\
\hline 31 & & 475 & & 480 & & 605 & \\
\hline Latossolo & Vermelho & Amarelo & $(\mathrm{I}, \mathrm{Vm})$ & & & & \\
\hline $18 / 06$ & & 150 & & 150 & & 280 & 300 \\
\hline 19 & & 120 & & & & & \\
\hline 20 & & 1.40 & & 380 & & 270 & \\
\hline $2 I$ & & 100 & & $\cdot$ & & & \\
\hline 22 & & 120 & & & & & 650 \\
\hline 2.3 & & .260 & & 410 & & & \\
\hline 24 & . & 200 & & & & 380 & \\
\hline
\end{tabular}


Tabela 7. Continuação

\begin{tabular}{|c|c|c|c|c|c|}
\hline \multirow{2}{*}{ Data } & \multicolumn{2}{|c|}{ Tratamento } & \% Água & Disponivel & \multirow[b]{2}{*}{70} \\
\hline & 10 & 30 & & 50 & \\
\hline $25 / 05$ & 150 & 190 & & & 420 \\
\hline 26 & 140 & & & & \\
\hline 27 & 160 & 200 & & 450 & \\
\hline 28 & 170 & 160 & & & 380 \\
\hline 39 & 150 & 160 & & 400 & \\
\hline 30 & 1.70 & 180 & & & \\
\hline $01 / 07$ & 220 & 230 & & 380 & 400 \\
\hline 02 & 200 & 210 & & & \\
\hline 03 & 210 & 220 & & 350 & \\
\hline 04 & .200 & 210 & & & \\
\hline 05 & 230 & 250 & & 370 & 450 \\
\hline 06 & 290 & 280 & & & \\
\hline 07 & 300 & 300 & & 600 & \\
\hline 08 & 310 & 270 & & . & 750 \\
\hline 09 & 300 & 260 & & 460 & \\
\hline 10 & 300 & 280 & & & \\
\hline 11 & 320 & 310 & $\cdot$ & 410 & 600 \\
\hline 22 & 340 & 300 & & & \\
\hline 13 & 250 & 230 & & 480 & 410 \\
\hline 14 & 210 & 250 & & & \\
\hline 15 & 270 & 280 & & 420 & 450 \\
\hline 16 & 290 & 240 & & & \\
\hline 17 & 400 & 320 & & 456 & 460 \\
\hline 18 & 275 & 210 & & & \\
\hline
\end{tabular}

Cont. 
Tabela 7. Continuação

\begin{tabular}{lcccc}
\hline & \multicolumn{2}{c}{ Tratamento $\%$ Agua Disponivel } \\
\cline { 2 - 4 } Data & 10 & 30 & 50 & 70 \\
\hline $19 / 07$ & 340 & 270 & & \\
20 & 330 & 265 & 540 & 500 \\
21 & 330 & 330 & 330 & \\
22 & 430 & 335 & 355 & 490 \\
23 & 280 & 230 & & \\
24 & 365 & 330 & 300 & \\
25 & 365 & 290 & & \\
26 & 460 & 320 & 540 & \\
27 & 340 & 328 & & \\
28 & 391 & 300 & 610 & \\
29 & 336 & 300 & & \\
30 & 380 & 365 & 465 & \\
31 & 370 & 340 & & 410
\end{tabular}


Tabela 8. Médias originais obtidas de 15 mudas em cada tratanento, por re petição, em relação a altura, diâmetro do pseudo-caule e matéria seca, das mudas de cebola na colheita.

\begin{tabular}{|c|c|c|c|c|c|}
\hline Solo & $\begin{array}{l}\text { Nível de } \\
\text { àgua }\end{array}$ & Repetição & $\begin{array}{l}\text { Altura } \\
(\mathrm{cm})\end{array}$ & $\begin{array}{c}\text { Diâmetro } \\
(\mathrm{mm})\end{array}$ & $\begin{array}{c}\text { Matéria } \\
\text { seca } \\
\text { (g) }\end{array}$ \\
\hline Terra & $70 \%$ consumo & 1 & 22,53 & 3,30 & 1,43 \\
\hline Roxa & Āgua Disponível & 2 & 24,73 & 3,20 & 1,50 \\
\hline Estruturada & & 3 & 24,13 & 3,09 & 1,50 \\
\hline \multirow[t]{10}{*}{ (TRE) } & & 4 & 25,26 & 3,29 & 1,50 \\
\hline & & 5 & 24,40 & 3,02 & 1,35 \\
\hline & & 6 & 22,06 & 3,00 & 1,20 \\
\hline & $50 \%$ consurno & 1 & 25,86 & 3,49 & 2,05 \\
\hline & Ågua Disponível & 2 & 28,0 & 3,79 & 2,45 \\
\hline & & 3 & 29,33 & 3,90 & 2,75 \\
\hline & & 4 & 30,06 & 3,82 & 2,90 \\
\hline & & 5 & 26,93 & 3,36 & 2,00 \\
\hline & & 6 & 30,33 & 3,78 & 2,55 \\
\hline & $30 \%$ consumo & 1 & 29,20 & 4,07 & 3,00 \\
\hline \multirow{8}{*}{ ( ) } & Āgua Disponivel & 2 & 28,33 & 4,02 & 2,55 \\
\hline & & 3 & 26,53 & 3,66 & 2,35 \\
\hline & & 4 & 29,80 & 4,45 & 3,00 \\
\hline & & 5 & 30,46 & 3,99 & 2,85 \\
\hline & & 6 & 27,80 & 4,35 & 2,90 \\
\hline & $10 \%$ consumo & 1 & 29,53 & 4,09 & 1,05 \\
\hline & Agua Disponível & 2 & 27,46 & 3,80 & 2,25 \\
\hline & & 3 & 27,26 & 4,20 & 2,50 \\
\hline \multirow[t]{3}{*}{$\cdot$} & & 4 & 28,26 & 3,94 & 3,15 \\
\hline & & 5 & 27,46 & 3,93 & 2,65 \\
\hline & & 6 & 26,06 & 3,71 & 2,35 \\
\hline
\end{tabular}


Tabela 8. Continuação.

\begin{tabular}{|c|c|c|c|c|c|}
\hline Solo & $\begin{array}{l}\text { Nivel de } \\
\text { água }\end{array}$ & Repetição & $\begin{array}{l}\text { Altura } \\
\text { (cm) }\end{array}$ & $\begin{array}{c}\text { Diârnetro } \\
\text { (mon) }\end{array}$ & $\begin{array}{c}\text { Matêria } \\
\text { seca } \\
\text { (g) }\end{array}$ \\
\hline Iatossolo & $70 \%$ consurno & 1 & 26,40 & 3,78 & 2,95 \\
\hline Verme lho & Água Disponível & 2 & 28,60 & 3,70 & 3,05 \\
\hline Anarelo & & 3 & 25,60 & 3,76 & 2,90 \\
\hline \multirow[t]{11}{*}{$(\mathrm{LVm})$} & & 4 & 27,60 & 4,02 & 3,20 \\
\hline & & 5 & 23,66 & 3,73 & 2,15 \\
\hline & & 6 & 25,13 & 4,00 & 3,25 \\
\hline & $50 \%$ consumo & 1 & 28,00 & 4,30 & 3,45 \\
\hline & Āoua Disponível & 2 & 28,20 & 4,46 & 3,60 \\
\hline & & 3 & 30,46 & 4,84 & 4,05 \\
\hline & . & 4 & 30,20 & 4,64 & 3,70 \\
\hline & & 5 & 29,46 & $4,9.2$ & 4,00 \\
\hline & & 6 & 28,93 & 4,77 & 3,70 \\
\hline & $30 \%$ consumo & 1 & 28,46 & 4,85 & 3,60 \\
\hline & Égua Disponível & 2 & 30,80 & 4,78 & 3,95 \\
\hline \multirow[t]{10}{*}{$\because$} & & 3 & 29,73 & 5,02 & 4,35 \\
\hline & & 4 & 30,26 & 4,66 & 3,70 \\
\hline & & 5 & 29,33 & 4,58 & 3,65 \\
\hline & & 6 & 27,93 & 5,17 & 4,35 \\
\hline & $10 \%$ consumo & 1 & 30,00 & 4,84 & 4,10 \\
\hline & Agua Disponível & 2 & 26,66 & 4,78 & 3,60 \\
\hline & & 3 & 29,13 & 4,31 & 3,25 \\
\hline & & 4 & 33,00 & 4,50 & 3,95 \\
\hline & & 5 & 29,60 & 4,91 & 4,05 \\
\hline & & 6 & 29,13 & 4,77 & 3,95 \\
\hline
\end{tabular}

